\title{
EL DESARROLLO ESPACIAL DE LAS COMUNIDADES CHACHAPOYAS BAJO LA DOMINACIÓN COLONIAL INKA Y ESPAÑOLA
}

\author{
James M. Crandall ${ }^{a}$
}

\begin{abstract}
Resumen
Los chachapoyas han sido percibidos como una entidad cultural periférica en relación con las otras sociedades de los Andes. Queda claro que la cultura material relacionada con los chachapoyas fue desarrollada antes de $1000 \mathrm{~d}$.C., pero lo que no queda claro es si tuvo un carácter uniforme a nivel regional. En los Andes prehispánicos la centralización urbana y la presencia de arquitectura con una separación clara de espacios se han utilizado como evidencias de las transformaciones sociales y politicas. Por otra parte, es probable que las conquistas de los inkas y los españoles hayan resultado en cambios radicales en las relaciones de trabajo, la economía y las prácticas religiosas de los grupos étnicos conquistados. En la actualidad hay pocas investigaciones que hayan estudiado cómo las prácticas sociales cambiaron bajo diferentes regimenes. En este estudio se emplea una perspectiva de escala para entender las implicancias de estos cambios en la región de Chachapoyas. El objetivo es comprender mejor el desarrollo de las comunidades chachapoyas. Este trabajo aborda la importancia de la centralización de una de estas comunidades, Purun Llacta de Soloco, y el papel de su arquitectura en los cambios en el desarrollo social y politico de los asentamientos que lo rodeaban.
\end{abstract}

Palabras clave: Chachapoyas, Amazonas, Imperio Inka, colonialismo español, doctrina, análisis espacial, plazas

\section{Abstract \\ THE SPATIAL DEVELOPMENT OF CHACHAPOYA COMMUNITIES UNDER INKA AND SPANISH COLONIAL DOMINATION}

The Chachapoya have come to be seen as a peripheral cultural entity in relation to the broader pre-Columbian Andes. While the material culture associated with the Chachapoya developed prior to AD 1000, it is unclear how uniform this process was on a regional level. In the pre-Columbian Andes, the development of centralized and partitioned monumental architecture has been commonly used as evidence for social and political transformations. Furthermore, the incursions of the Inka and Spanish conquests likely imposed radical changes in the labor, economic, and religious practices of conquered ethnic groups, yet little work has addressed how social practices changed under different regimes. This paper utilizes a scalar perspective to understand the implication of these changes for the Chachapoya region. To better understand the development of Chachapoya communities, this paper addresses the significance of centrality for one such community, Purun Llacta de Soloco, and the role that the construction of its architecture and changes to the surrounding settlement rendered in its social and political development.

Keywords: Chachapoya, Amazonas, Inka Empire, Spanish colonialism, doctrina, spatial analysis, plazas

\footnotetext{
${ }^{a}$ Department of Anthropology, University of Florida Correo electrónico: jamescrandall@ufl.edu
} 


\section{Introducción}

Las conquistas inka y española de los chachapoya no fueron procesos históricos breves, sino eventos perdurables de ocupación, impuestos por potencias coloniales profundamente distintas. Los inkas conquistaron la región por primera vez en la década de 1470 d.C., pero la incorporación política de sus diversos pueblos parece haber tenido lugar después de una larga serie de acciones militares (Schjellerup 2005). La presencia inka en Chachapoyas se puede ver a través de la presencia de pequeñas instalaciones en las comunidades que fueron fundadas durante el Horizonte Tardío o antes (ibid.). La presencia material del imperio sirvió para integrar la fuerza laboral local al sistema imperial de tributarios, lo cual se observa a través de las carreteras, los tampus y los almacenes que manifiestan el poder económico de la región de Chachapoyas (Narváez 1987, 1996; Church 1997; Muscutt 1998; Guillén 2000; Ruiz Estrada 2004; Schjellerup 2005, 2008, 2015; Ruiz Barcellos 2013). La ocupación inka en la región central de Chachapoyas se ha estudiado en sitios como Cochabamba, donde se observa el estilo imperial en la elaboración de las piedras y en la planificación centralizada, que se parecen a conjuntos imperiales que se encuentran al sur de Perú (Schjellerup 1984). Las instalaciones más pequeñas de la región de Chachapoyas, como Inka Llacta y Pósic (Schjellerup 2015, este volumen), también manifiestan los conceptos inkas de planificación cívica como los ushnus, las qollqas, y los kallankas.

Aunque la conquista inka tuvo efectos notables en la región, la conquista española tuvo un impacto aún más grande en las estructuras de las comunidades de Chachapoyas. Desafortunadamente, este período ha recibido muy poca atención de parte de los arqueólogos. Con la fundación de San Juan de la Frontera de los Chachapoyas en 1538 d.C., este pueblo sirvió como un modelo regional o arquetipo de las reducciones que se fundarían en las décadas de 1570 y 1580 . Si bien los españoles admiraban la planificación centralizada y las calles cuadriculadas de Cajamarca y Cuzco, la planificación de las comunidades chachapoyas no cumplía con los conceptos urbanos de los españoles y su ideal social de civitas, o la constitución del cuerpo social (Cummins 2002a; VanValkenburgh 2012). Como resultado, el establecimiento de la Comunidad Andina se llevó a cabo en los siglos XVI y XVII a través de una serie de experimentos sociales radicales que tuvieron efectos traumáticos en los pueblos chachapoyas. Sin embargo, en los primeros cuarenta y cinco ańos de la conquista, los administradores y encomenderos españoles impusieron su modelo de vida social en las comunidades preexistentes. Para los inkas y los doctrineros españoles, la reconstitución de las comunidades periféricas fue un acto que sirvió a sus agendas políticas, económicas y religiosas. Sin embargo, los vestigios de muchos asentamientos exhiben una organización de "planes mixtos» (Hyslop 1990) que incorporan formas chachapoyas con arquitectura vernácula y reflejan la fundación de centros administrativos imperiales y de espacios públicos.

Los estudios arqueológicos de las relaciones espaciales no tratan al espacio como un objeto carente de contexto social. Como Edward Soja (1980: 208) ha observado: «La estructura del espacio organizado no es una estructura independiente y con sus propias leyes autónomas de construcción y transformación, tampoco es simplemente una expresión de la estructura de clases que surge de las relaciones sociales de producción. Representa, más bien, un componente definido dialécticamente de las relaciones generales de producción, las relaciones que son al mismo tiempo sociales y espaciales». (traducción del autor).

Con este fin, el presente estudio analiza la manera en que los regímenes de poder inka y español impactaron los aspectos espaciales del territorio en el valle de Sonche de los chachapoya, para así identificar cómo tales aspectos se vinculaban con las relaciones sociales de producción.

Este proceso requiere la consideración de las relaciones entre la constitución espacial de las comunidades chachapoyas y los modos de producción que promovieron su desarrollo y continuidad. Por lo tanto, en este documento resumo los avances de investigaciones realizadas en el valle de Sonche desde la perspectiva de los registros históricos y arqueológicos. Luego analizo el desarrollo y la utilización del espacio en una de estas comunidades, mediante datos obtenidos por mapeo y la excavación de los sitios del Proyecto Purun Llacta de Soloco, distrito de Soloco, Perú (2014-2015). 


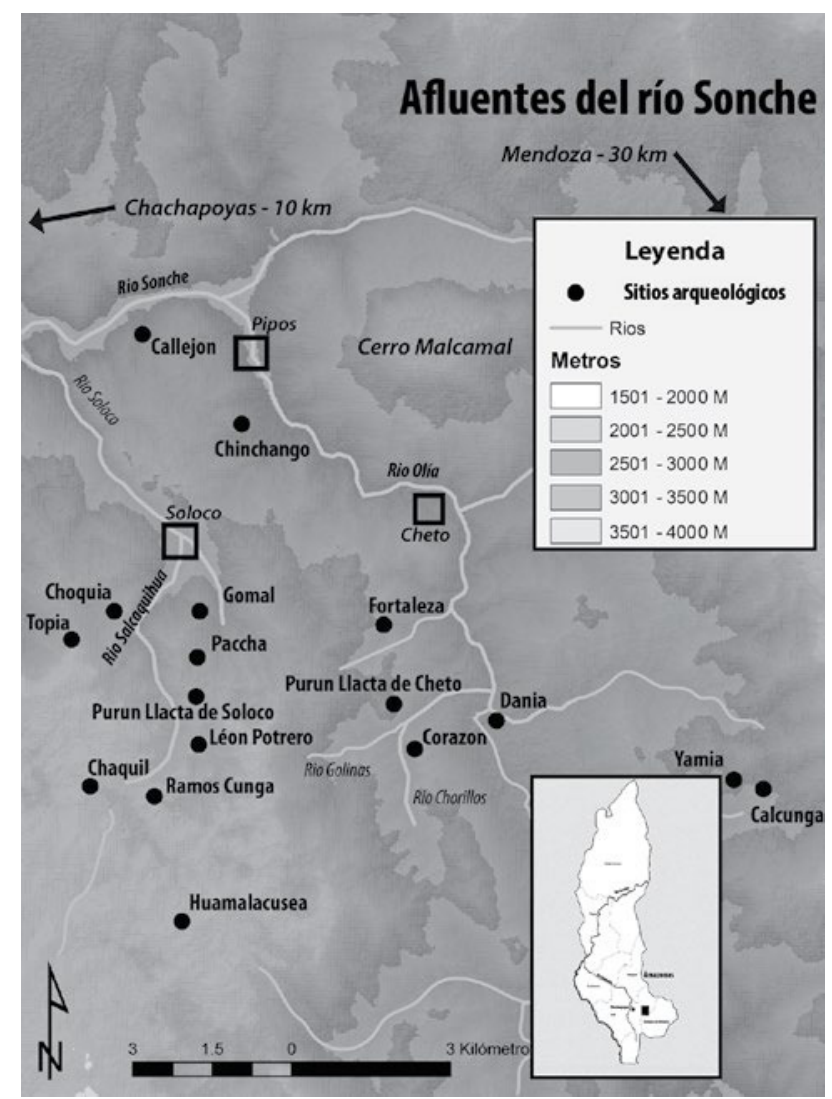

Figura 1. Sitios arqueológicos cerca del rio Sonche (dibujo por J. M. Crandall).

En particular, examino cómo los lugares centrales fueron impactados por las relaciones espaciales de la comunidad, y cómo cambiaron los modos de producción durante los períodos inka y colonial temprano en Purun Llacta de Soloco. En otras palabras, trato de entender cómo la planificación cívica imperial impactó el desarrollo de la comunidad. Finalmente, presento un análisis espacial breve en el que examino el desarrollo relacional diacrónico de la arquitectura de Purun Llacta y considero la importancia de estos cambios en el contexto de las épocas inka y colonial temprana.

\section{El valle de Sonche y sus vecinos}

El valle de Sonche se ubica 15 kilómetros al este de la ciudad moderna de Chachapoyas. Las convergencias de los ríos locales albergan varias comunidades modernas, que están rodeadas por mosaicos de paisaje de ceja de selva. Los sitios arqueológicos son abundantes y se encuentran distribuidos a lo largo del río Sonche y en otros lugares, como las cimas de cerros cercanos a las convergencias de los ríos influyentes (Fig. 1). Una de las formaciones geológicas más sobresalientes de la región es el cerro Malcamal en la confluencia de los ríos Sonche y Olía. Bajo su sombra se encuentran algunos de los asentamientos precolombinos más monumentales que se hayan documentado en la región central de Amazonas.

Los sitios precolombinos en la región de Sonche muestran evidencias de desarrollo que son representativas de las amplias redes sociopolíticas que caracterizaron al Período Intermedio Tardío (Guengerich 2015). Los materiales culturales de la región muestran también características expresivas de esta época. En centros regionales como Purun Llacta de Cheto y Purun Llacta de Soloco ${ }^{1}$, 
es posible hallar cerámica con formas y técnicas decorativas parecidas a las de la fase Kuélap que Ruiz Estrada (2009) identificó en el sitio de Kuélap en asociación con el Período Intermedio Tardío (observación personal). La arquitectura de esta región parece carecer de frisos y de piedras talladas con diseños (Fabre 2006) ${ }^{2}$.

Purun Llacta de Cheto, uno de los sitios más grandes de la región, fue identificado en 1947 (Ruiz Estrada 2004). Este sitio cuenta con varios cientos de estructuras (Ruiz Barcellos 2013: 217). Algunos de los edificios tienen bases rectangulares grandes, una característica arquitectónica sobresaliente. Las pocas excavaciones en estructuras rectangulares en Purun Llacta de Cheto revelaron cerámica y artefactos de cobre de estilo inka (Ruiz Barcellos 2001), lo cual sugiere que el sitio probablemente fue incorporado por los inkas como un centro agrícola y administrativo (Ruiz Estrada 2004). Purun Llacta de Cheto está ubicado cerca de abundantes terrenos aptos para la agricultura, sus residentes habrían tenido acceso directo a las tierras bajas ubicadas al sureste, donde está el valle de Cochamal, así como al valle de Huayabamba ${ }^{3}$. El sitio se orientó en torno a pequeñas plazas y a varias de las redes de carretera no documentadas de la región.

La orientación de los sitios al Qhapaq Nan se encuentra con frecuencia en los distritos de Cheto y Soloco y en las comunidades satélites más pequeñas, como Gomal, Léon Potrero, Chaquil, Fortaleza, Corazón y algunos sectores de Purun Llacta de Soloco y Cheto. Estos sitios habrían estado claramente integrados a esta red. La presencia de edificios al lado de las carreteras regionales sugiere que un esquema de organización más grande gobernaba la constitución de los espacios sociales. Por ejemplo, una sección del Qhapaq Nan entre Gomal y Purun Llacta de Soloco incluye el sitio de Paccha, con una estructura parecida a las bases circulares de otras partes de Chachapoyas. Paccha tiene un manantial sobre el cual se construyó un edificio desde donde se distribuye agua todo el año — desde aquellos tiempos hasta la actualidad-, lo cual evidentemente fue diseñado para capturar, controlar y filtrar el agua mediante el uso de técnicas hidráulicas inkas (parecidas a las descritas en Cuzco por Fairley 2003). Por otro lado, muchos sitios de la región, tales como Chaquil (Fabre et al. 2008), Purun Llacta de Cheto, Soloco, Léon Potrero y Gomal, tienen estructuras en forma de «D» (Fig. 2). Estos edificios se distinguen de las casas circulares tradicionales chachapoyas por tener una fachada plana, aunque la parte trasera tiene forma curvada. También se asientan sobre una plataforma baja, con cornisas en la parte superior y que a veces comparten plataformas entre sí. Las estructuras en forma de «D» se han registrado en Kuélap (Narváez 1987), así como en Inticancha en Uchucmarca (Thompson 1976), pero con poca frecuencia. La recuperación de cobre inka en los primeros pisos de dos de estas estructuras por el Proyecto Purun Llacta de Soloco, y la presencia de este estilo de arquitectura en Purun Llacta de Cheto, sugieren que este estilo arquitectónico proliferó durante el Horizonte Tardío. Las estructuras en forma de «D» en Purun Llacta de Soloco posiblemente fueron estructuras ceremoniales como la estructura de la plaza colonial en el Sector A (Estructura \#63). La integración de estas estructuras en la zona céntrica Chachapoya, Sector B, puede indicar una presencia temprana en la región de Chachapoyas de esta forma arquitectónica. Esta representa probablemente una adaptación a la similar arquitectura ceremonial que se encuentra en sitios wari y en otras partes de los Andes (Cook 2001).

Durante los períodos tumultuosos de la conquista inka, a finales del siglo XV e inicios del XVI, esta región fue foco de las preocupaciones económicas imperiales, debido a la constante inestabilidad política. Se dice que Apu Alonso Chuquimis, una figura política polémica nombrado hunokuraka de Cochabamba y Leymebamba, fue seleccionado por los inkas a pesar de las críticas de los curacas locales (Schjellerup 2005: 133). Él había sido curaca de Pipos ${ }^{4}$, una comunidad conformada por dos pachakas o grupos de linaje (Espinoza Soriano 1967: 242). Schjellerup (2005: 133) ha sugerido que la presencia de Chuquimis, un curaca de la región norte de Chachapoyas (Vizcarra [1574] en Espinoza Soriano 1967), provocó luchas políticas que fraccionaron a la región durante un tiempo. Los problemas políticos internos entre los grupos étnicos y las regiones geográficas de Chachapoyas probablemente se pueden atribuir a la fragilidad de la paz lograda por la conquista inka. Cuando Atawallpa recorrió brevemente la región de Chachapoyas, el curaca Francisco Guamán lo guio en su recorrido a través de la parte norte de los territorios de Chachapoyas hacia el Valle de Pipos (el río 


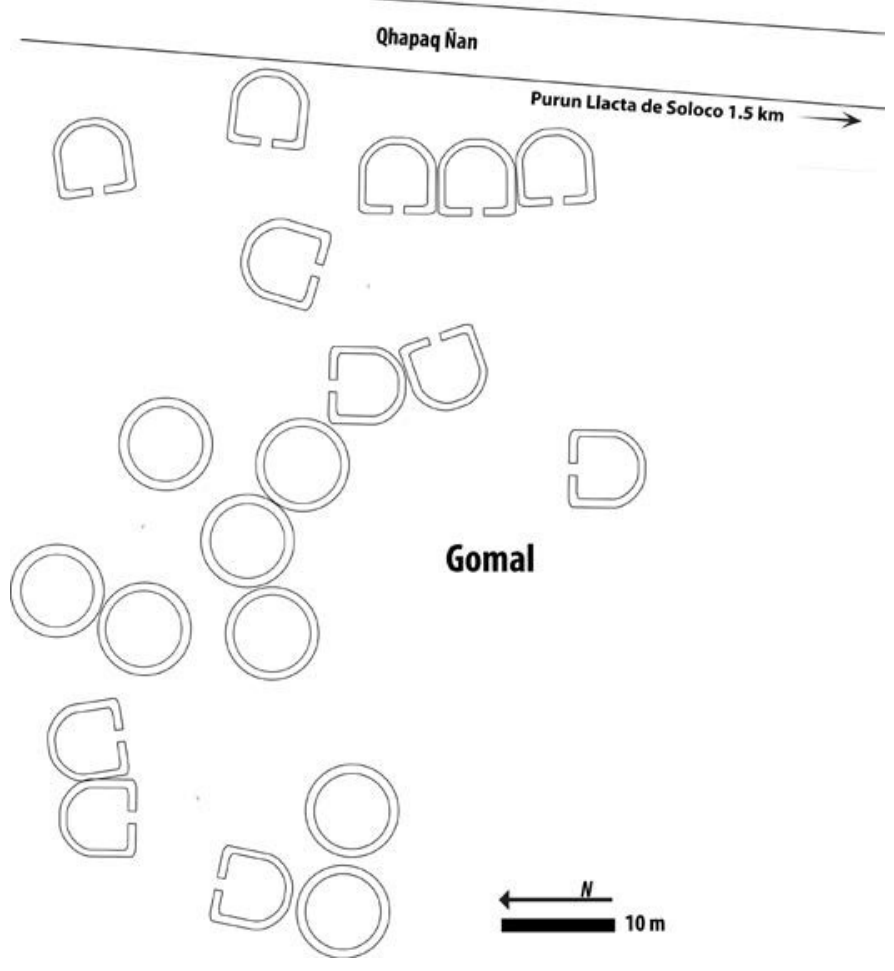

Figura 2. Croquis del sitio de Gomal (dibujo por J. M. Crandall).

Sonche) y Cheto (Diego de Vizcarra [1574] en Espinoza Soriano 1967: 232). El hecho de que el centro administrativo de Purun Llacta de Cheto fuera suficientemente importante para recibir una visita real refleja su importancia en la región. Dicha referencia a la gente del valle sugiere que el término «Pipos» posiblemente no indicaba un lugar, sino más bien el nombre del ayllu de los chachapoya.

La constitución de Pipos como un ayllu con dos grupos de linaje puede indicar que los sitios de Purun Llacta de Cheto y Purun Llacta de Soloco ya eran lugares relacionados antes de que fueran incorporados en el plan imperial de la conquista inka. Asimismo, los prefijos de los topónimos de los sitios tal vez representan una pista en cuanto a la estructura de estos lugares antes de la reorganización española de la región. En quechua, purun o purum puede significar un grupo de «extraños» o «antepasados primitivos» (Ruiz Barcellos 2011), y puede reflejar la representación de las comunidades o llaqtas construidas después de la conquista española, cuando los sentimientos locales hacia los antepasados y los inkas quedaron concretados en los topónimos locales. En cualquier caso, está claro que el valle de Sonche y estas poblaciones eran de gran interés para los inkas y su proyecto de dominio regional.

Las reducciones de Cheto y de otros sitios de la región se llevaron a cabo en 1583 (Cristóbal de Miranda 1925 [1583]: 217) ${ }^{5}$. Santo Toribio de Mogrovejo visitó la región de Sonche en 1595, y describió a la comunidad de Cheto como un anexo del Chasmal, un pueblo más pequeño al norte del río Sonche. Sobre Cheto Mogrovejo escribió que consistía en «98 tributarios, y 50 indios reservados y de confesión 367, y Animas 528" (en Benito Rodríguez 2006: 116). Cheto obviamente fue una comunidad relativamente grande durante el siglo XVI, que se incorporó de manera total al ideal español de civitas. Sin embargo, comunidades vecinas como Chelel y Chasmal ya estaban en decadencia. La alteración de las condiciones sociales obligó a muchos de sus miembros a trasladarse a otros sitios, tal vez como resultado de las crecientes demandas de trabajo por parte 
de los encomenderos ${ }^{6}$. Esta presión parece haber impactado las relaciones sociales hasta el punto de que el curaca principal de Chasmal decidió buscar mejores opciones en Lima en la década de 1570 (Ramos 2011: 30). En 1569, Toledo ordenó la reducción de todo el Perú, lo cual alteró para siempre la vida social andina. Al mismo tiempo, los sacerdotes de las órdenes religiosas de La Merced, San Francisco y San Agustín establecieron doctrinas en toda la región del Amazonas (Armas 1953).

Los cambios sociales de los siglos XVI y XVII impactaron tanto la vida de las comunidades indígenas que muchas — entre ellas Timbal y Chasmal— rápidamente disminuyeron en población, casi al punto de desaparecer entre 1583 y 1593 (Mogrovejo [1595], en Ruiz Estrada 2011 [1586] y Cristóbal de Miranda [1583]). Al finalizar el siglo XVI, las comunidades de toda la cuenca del río Sonche sufrieron una disminución de la población de un 11\% por año (Cook 1981: 195-197). Cuando Martínez de Compañón (1792: 216-217) visitó la región en 1787, dijo de Cheto que «se halla una las siete leguas y Tiene tres anexos Bastante infelices y despoblados. A la una legua de distancia está el de Soloco, una las dos el de Chelel, y el de Cochamal una las doce, que contienen muchos trasitios y ríos Peligrosos [sic].».

Al parecer, la baja densidad de población de la región no había cambiado mucho cuando el geógrafo Antonio Raimondi (1874: 409-410) visitó las comunidades de Pipos y Cheto en 1867. Las describió como pequeñas aldeas de poca importancia, con una docena de casas cada una; las vio como una parada de descanso en su viaje hacia el este. Al momento de la visita de Raimondi, la condición de estas comunidades había cambiado radicalmente en relación a los siglos anteriores. Estos cambios tuvieron impactos sociales amplios en todo el valle de Sonche. Por ejemplo, el pueblo de Chelel, anteriormente un anexo de Chasmal, se convirtió en un anexo de Cheto (Martínez de Compañón 1792: 218). Tales cambios en las fronteras políticas y eclesiásticas fueron una reacción a los declives poblacionales, sobre todo durante las epidemias masivas de la década de 1590 (Cook 1981, Schjellerup 2005: 56-58).

Si bien se han realizado algunos proyectos arqueológicos en la región de Sonche, está claro que, durante el Horizonte Tardío y los períodos coloniales, la población local mantuvo tradiciones materiales distintas, al mismo tiempo que fue impactada por sistemas políticos extensos que afectaron las prácticas cotidianas. Durante el período inka, la región llegó a formar parte interdependiente de las instituciones sociales del imperio a través de su conexión con los centros administrativos establecidos en sitios como Purun Llacta de Cheto. Después de la conquista española, se fundaron nuevas comunidades para organizar la mano de obra regional, pero estas tuvieron el efecto inesperado de destruir el sistema de organización del trabajo que había sido diseñado con el propósito de explotar a la población local. Antes de la implementación de la política de reducciones, las conquistas inkaica y española ya habían impactado las comunidades chachapoya según sus distintos modelos ideológicos de creación de sujetos aptos para gobernar. Para entender estos cambios, examino en seguida la constitución del espacio cívico de Purun Llacta de Soloco.

\section{Purun Llacta de Soloco y sus espacios}

Purun Llacta de Soloco (Fig. 3) se encuentra a 3,5 kilómetros al sur de la actual comunidad de Soloco y a 3,7 kilómetros al oeste de la zona arqueológica de Purun Llacta de Cheto. Está ubicado a una altura de 2950-3018 msnm en la cima del cerro Liclic. El sitio cuenta con una imponente vista de los cerros circundantes, en muchos de los cuales se encuentran pequeñas ruinas precolombinas, y está flanqueado por los ríos Soloco y Sallcaquihua. El sitio está dividido en dos sectores. La mayor parte del Sector A se encuentra en una zona baja y plana cerca del Qhapaq Nan, y cuenta con las más tardías construcciones del sitio, incluso de los períodos inka y español. El Sector B abarca la parte sur del sitio, y se centra en su cima, rodeado de casas que se ubican encima de terrazas altas. El desarrollo de este sector parece haber empezado antes de la conquista inka, pero al parecer fue ocupado durante las dos épocas coloniales. 


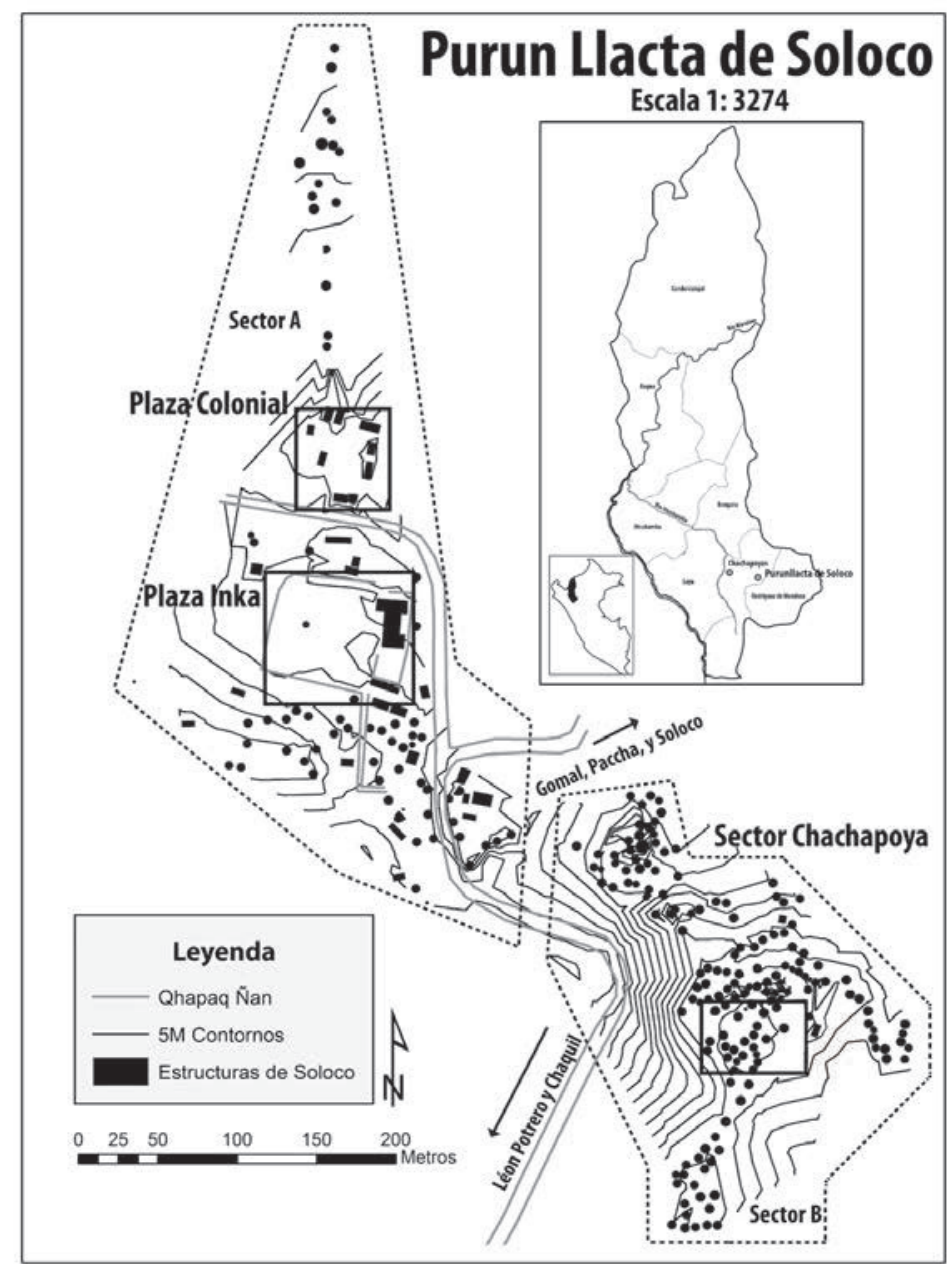

Figura 3. Croquis de Purun Llacta de Soloco (dibujo por J. M. Crandall).

Los restos más antiguos encontrados en el lugar de Purun Llacta de Soloco se remontan al Horizonte Temprano y al Período Intermedio Temprano. El Proyecto Purun Llacta recuperó fragmentos de cerámicas pintadas con diseños «rojo sobre blanco» (Fig. 4) en el ápice del sitio, en un contexto asociado con el único entierro de un adulto joven. Estas cerámicas comparten pastas y diseños con otras cerámicas tempranas recuperadas en los Andes nororientales, pero no se pueden relacionar con seguridad a categorías establecidas como las fases Colpar (Church 1996) o Tosán (Koschmieder 2012: 36). En las discusiones arqueológicas, el surgimiento sociopolítico de los chachapoya se destaca como un evento que ocurrió durante el Período Intermedio Tardío, marcado por la presencia de arquitectura circular a escala amplia después de 1000 d.C. (Church y von Hagen 2008). Sin embargo, está claro que muchos cerros de la región de Chachapoyas fueron ocupados o utilizados en un período considerablemente más antiguo (v.g. Schjellerup 2005: 347-354; Guengerich 2014a).

El grupo de casas en el distrito central es el más denso. En este sector, las casas miden en promedio 5,5 metros de diámetro. Las estructuras circulares más pequeñas del sitio miden 3,2 metros, mientras que las mayores alcanzan 8,7 metros. Esta agrupación de casas se extiende sobre la plataforma principal del sitio. Esta plataforma fue construida con piedras calizas cortadas para crear una fachada o muro de 5,2 metros de altura que rodea el distrito central, el cual mide 52 por 44 


\section{Purunllacta de Soloco - Sector B - Unidad 20}
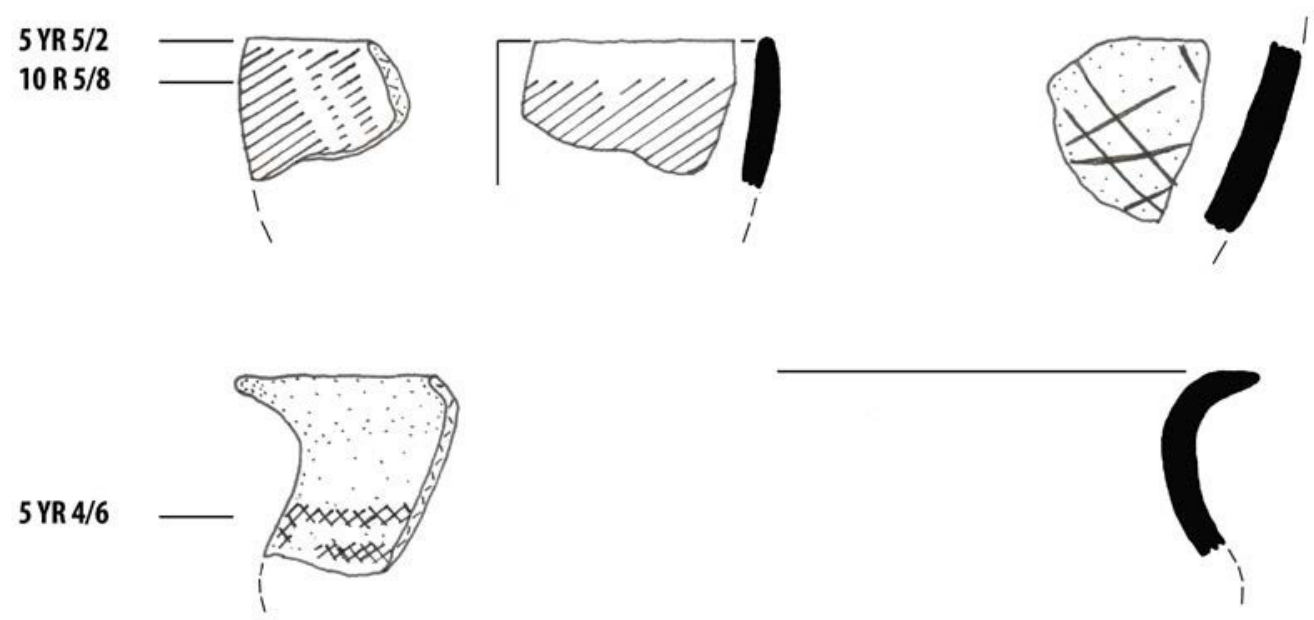

$10 \mathrm{~cm}$

Figura 4. Cerámicas tempranas en el sector Chachapoya en Purun Llacta de Soloco (dibujo por J. M. Crandall).

metros (Figs. 5 y 6). Este muro central comparte muchas características arquitectónicas con casas de toda Chachapoyas, por ejemplo, las cornisas sobresalientes. Este sector es el más restringido del sitio y solo se puede entrar a él a través de dos escaleras integradas en el noreste y el sur de las paredes de la plataforma.

El modelo de aglutinamiento ( $c f$. Narváez Vargas 1987) de las casas que está presente en el distrito central ha sido registrado en toda la región de Chachapoyas (Fabre 2006: 92-94; Guengerich 2014a). Las casas organizadas en agrupaciones aglutinadas en Purun Llacta se construyeron por lo general de manera adyacente, con paredes colindantes, pero no compartidas. Sin embargo, cada edificio se construyó de forma independiente. En conjunto, este proceso de desarrollo de la comunidad produjo una partición del espacio que también se manifiesta en la plaza chachapoya presente en el Sector B. Esta plaza cubrió los edificios y los entierros anteriores del distrito central. La presencia de cerámica en capas posteriores indica que la última permutación del distrito central tuvo lugar en el Período Intermedio Tardío/Horizonte Tardío, la cual incluyó la pavimentación de la superficie de la plaza con lajas de caliza de un grosor estandarizado (Fig. 7). La construcción del piso con lajas de piedra caliza también caracterizó a dos casas del Período Intermedio Tardío en el sitio. Se han identificado plazas pequeñas en sitios chachapoya como Kuélap (Narváez 1987), Monte Viudo (Guengerich 2014b), Olán (observación personal) y otros. Además, la pavimentación del espacio público entre las casas compartidas en Purun Llacta representa una expresión de ideas compartidas con otros sitios sobre el espacio cívico chachapoya (Bonavia 1968: 84; Bueno y Cornejo García 2009: 31).

Las personas que se acercaban al sector central de Purun Llacta durante la época chachapoya habrían circulado por una serie de terrazas altas que servían para restringir el espacio entre las plataformas, un modelo de organización en las comunidades chachapoya que Narváez (1987) ha llamado «lineal». La interconexión de estas plataformas y su integración en una cadena más amplia de plataformas aún más estrechas sugiere alguna forma de organización comunal, tal vez representando un conjunto de familias. Una persona que se acercaba a la terraza más alta de este sector, antes de llegar a la plataforma más alta en el distrito central, habría pasado a través de una sola entrada ubicada en una rampa grande con acceso restringido (Fig. 8). En los sitios chachapoya, 


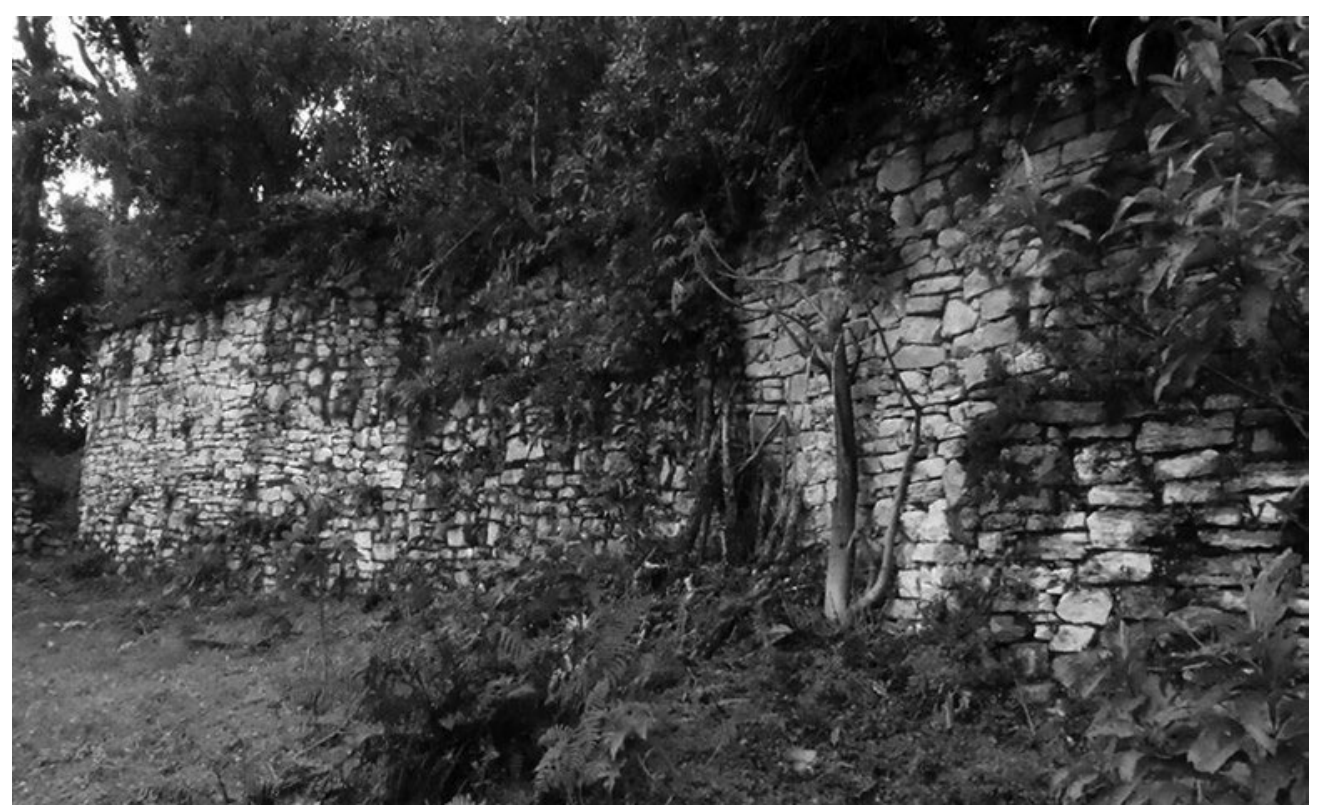

Figura 5. Muro alrededor del sector Chachapoya en Purun Llacta de Soloco (foto por J. M. Crandall).

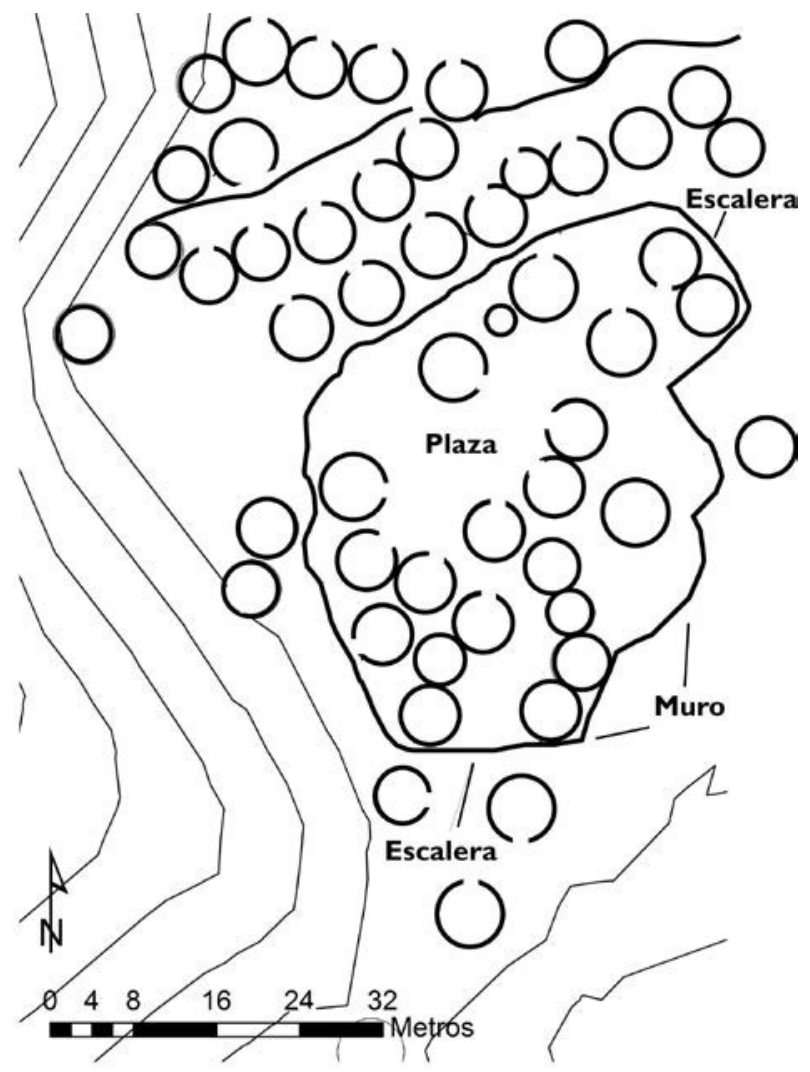

Figura 6. Croquis del sector Chachapoya en Purun Llacta de Soloco (dibujo por J. M. Crandall). 


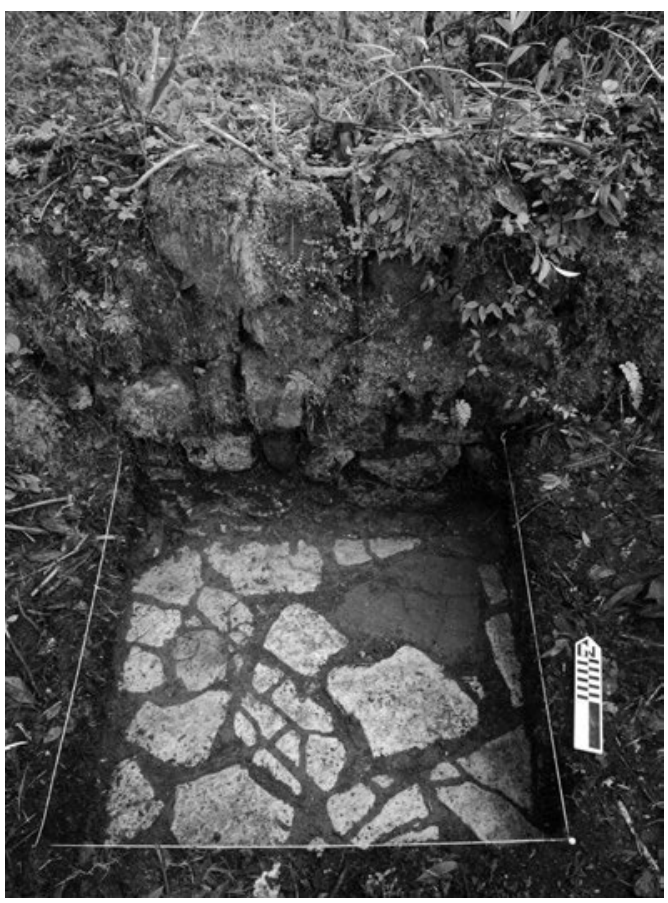

Figura 7. Lajas en la plaza del sector Chachapoya en Purun Llacta de Soloco (foto por J. M. Crandall).

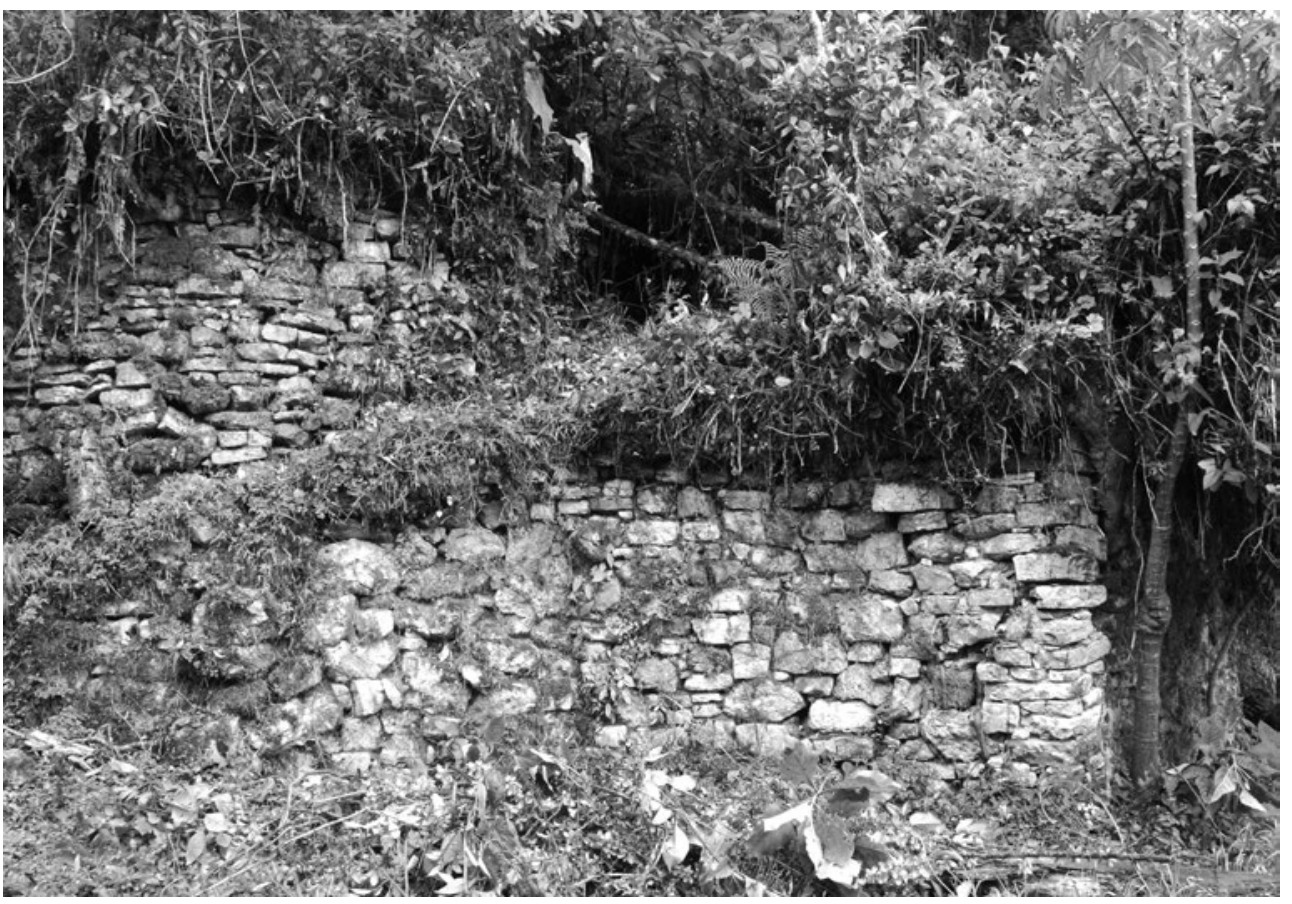

Figura 8. Rampa al sector Chachapoya restringido en Purun Llacta de Soloco (foto por J. M. Crandall). 
las terrazas fueron una necesidad topográfica, y la preocupación por la topografía probablemente ayudó a dar forma al desarrollo estilístico de la arquitectura vernácula chachapoya (ver Guengerich 2014b). Las seis terrazas de dos metros de altura en el extremo norte del sector chachapoya posiblemente cumplieron varias funciones. Estabilizaron las estructuras contra la degradación del medio ambiente; además, la morfología orientaba el desarrollo de la comunidad según las líneas y las obligaciones filiales, protegiendo a los grupos de parentesco en la comunidad. Estudios futuros podrán examinar la relación de grupos de hogares y proporcionar datos útiles para la reconstrucción de las relaciones sociales de los chachapoya antes de la conquista inkaica. Esta forma de alteración cívica, que implicó la modificación de las terrazas para incluir rampas de acceso estrechas que daban paso a las casas, indica que los modos de reproducción social se fundamentaron en la unidad de la casa. A su vez, las casas se integraron para formar una comunidad y así producir estructuras comunitarias más complejas según los conceptos ideológicos de los chachapoya.

$\mathrm{El}$ «sector Chachapoya» no representa un período temporal de uso, sino más bien su aspecto arquitectónico. Por ejemplo, de cinco casas que fueron excavadas en este sector, tres contenían cerámica Fase Kuélap del Período Intermedio Tardío. Además, la mayor parte de las fases finales de la ocupación en Purun Llacta contienen ejemplos de cerámica de origen Horizonte Tardío y Colonial. El conjunto del sector Chachapoya indica que muchas de las casas fueron ocupadas intensivamente durante el Período Colonial Temprano. Se encontró muchos entierros en los centros de las casas, debajo de las entradas y en las estructuras rectangulares.

El entierro mejor conservado fue encontrado en una tumba ubicada en el centro de una casa circular (Estructura \#98). La excavación de esta estructura permitió el hallazgo de tres entierros humanos a lo largo del eje central de la casa, asociados con distintas fases de ocupación. Cada vez que un individuo era enterrado, se construía un nuevo piso. Durante la segunda y última fase de la ocupación de esta estructura, se construyó una tumba de piedra caliza y batanes rotos para depositar a un hombre adulto (Fig. 9). Los materiales enterrados con el individuo son representativos de un conjunto híbrido (Fig. 10). Por ejemplo, se colocaron unas pinzas de cobre en su cabello, las cuales recuerdan a objetos de cobre producidos en la Costa Central del Perú a finales de los siglos XV y XVI (Owen 2012: 169). Artefactos similares de cobre también han sido descubiertos en el distrito de Luya (Koschmieder et al. 2014: 32). Se colocaron tres instrumentos de hueso en el cráneo y las caderas. Además, se depositaron una jarra colonial y un aríbalo de estilo inka, de fabricación local encima del conjunto. Un collar de treinta chaquiras turquesas de Nueva Cádiz adornaba su cuello. Las chaquiras vidrias en forma de diamantes de Nueva Cádiz probablemente se produjeron en Venecia o Andalucía, y se pueden vincular a un momento restringido de la historia colonial en el que las cuentas de vidrio se intercambiaban ampliamente en todo el continente americano. No se encuentran en contextos coloniales españoles después de 1550-1560 (Francis 2009: 67-68). Estas chaquiras coloniales se recuperan con frecuencia de contextos funerarios. Como resultado, las cuentas de Nueva Cádiz reflejan las redes económicas generales de un período limitado, cuando los representantes del imperio interactuaban con los curacas locales en cadenas de intercambio de escala intercontinental.

Entre las características definitivas de Chachapoyas se encuentran los complejos funerarios, los cuales variaban según la región y los distintos modos de expresión de identidad, como las chulpa o sarcófagos. Las prácticas mortuorias tienen la capacidad de alterar íntimamente los espacios mundanos, y adquieren significado en el contexto de redes más amplias de prácticas sociales. En el curso de las excavaciones en Purun Llacta, el proyecto descubrió los restos de varios entierros humanos $(\mathrm{N}=16)$. Nueve de estos fueron enterrados en forma de bultos y debajo de los pisos de las estructuras ${ }^{7}$. Cuatro de los entierros correspondían a personas menores de diez ańos. Estos subadultos, entonces, componen una proporción significativa de los entierros, y todos se fechan al período inka-colonial. Este descubrimiento apoya la documentación histórica de los altos índices de mortalidad a fines del siglo XVI debido a las epidemias (Cook 1981). Los entierros bajo los pisos de las casas también se han encontrado en otros sitios chachapoya (Koschmieder 2014, Toyne y Narváez 2014, Toyne y Narváez este número). La presencia de los entierros en Purun Llacta, desde 


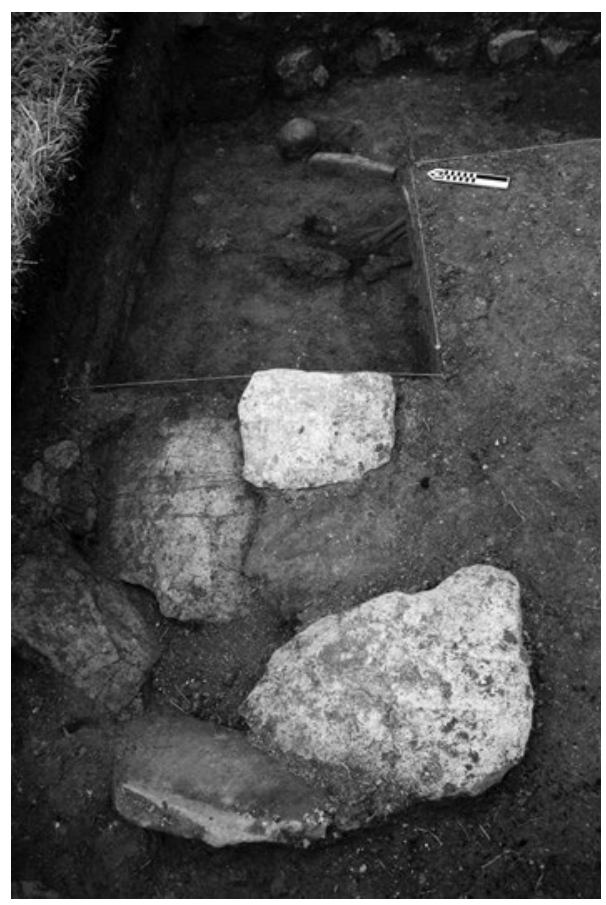

Figura 9. Las piedras de la tumba colonial en la Est. \#98 de Purun Llacta de Soloco (foto por J. M. Crandall).

recién nacidos hasta adultos mayores, sugiere que la práctica doméstica de manejo de los cuerpos fue una actividad familiar estandarizada. Esto resulta sorprendente cuando se tiene en cuenta que muchas sociedades de la América precolombina establecieron los derechos y obligaciones sociales a través de la consanguinidad y de las ideas culturales de ascendencia filial. En los Andes, «el vivir con los antepasados» significaba que tales obligaciones continuaban después de la muerte (Ramírez 2005). Estas relaciones eran afirmadas con el entierro de los antepasados debajo de los pisos de casas circulares.

Se encontraron seis chulpas en Purun Llacta de Soloco, y de estas dos usaron afloramientos de piedras del cerro. Las otras cuatro chullpas pequeñas contaron con puertas o entradas abiertas. Aunque solo una de estas no fue dañada, los huaqueros no destruyeron los contextos de manera completa. Por lo tanto, se puede elaborar algunas descripciones generales sobre las prácticas funerarias de la comunidad. Existen varias cuevas a menos de un kilómetro al oeste y al sur del sitio que tienen entierros humanos, pero no se ha registrado cuántos individuos albergaban (pero ver Fabre et al. 2008). A diferencia de los grandes complejos de abrigos rocosos como La Petaca (Epstein y Toyne 2016, Toyne y Anzellini este volumen) y Revash, que albergaban a cientos de entierros además de grandes construcciones funerarias, las chullpas de Purun Llacta eran muy pequeñas y es probable que solo hayan tenido una o dos personas cada uno ${ }^{8}$. Con la excepción de una tumba en la plaza del Sector Chachapoya, todas las chullpas se localizaban en los márgenes del sitio y miraban hacia los cerros adyacentes. La ubicación de los recintos funerarios en la periferia de las comunidades fue una práctica común en Chachapoyas (v.g. Guengerich 2014a: 93, Narváez Vargas 1996: 97), y es probable que las ceremonias funerarias hayan tomado la forma de prácticas que ocurrían en los límites de la comunidad (Crandall 2012).

Las condiciones en que los cuerpos humanos son tratados luego de la muerte son indicadores valiosos de las relaciones sociales y políticas de los vivos. Varios investigadores han puesto énfasis en el rol que los antepasados inkas y pre-inkas desempeñaron como agentes activos en los sistemas sociales (Dillehay 1995; Ramírez 2005; Shimada y Fitzsimmons 2015). Los espacios en que fueron enterrados probablemente estaban ligados a las relaciones sociales entre las comunidades y los muertos; por lo tanto, un estudio del espacio cívico incluye un estudio de los entierros ancestrales. 


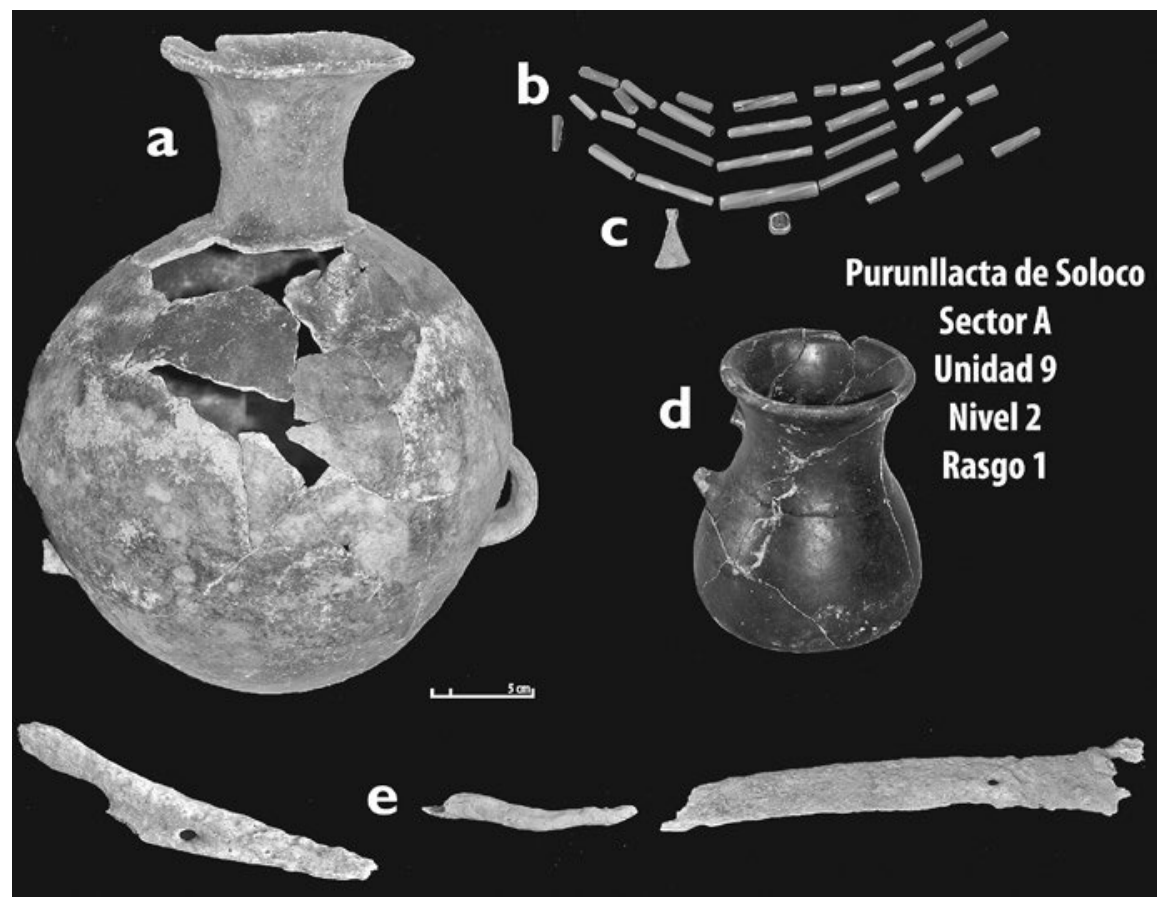

Figura 10. Los artefactos encontrados con el entierro colonial en la estructura \#98 de Purun Llacta de Soloco: a) aribalo (posiblemente de manufactura local), b) jarra colonial, c) treinta chaquiras de vidrio de estilo Nueva Cadiz, d) pinzas de cobre, e) herramientas de hueso (foto por J. M. Crandall).

Por ejemplo, se cuenta que el cadáver del curaca Chiquimis de Pipos fue extraído de una peña y luego sepultado bajo tierra para deshonrarlo por su supuesta participación en la muerte de Wayna Qhapaq (en Espinoza Soriano 1967; Schjellerup 2005). Recientemente, estudiosos han observado que el acto de exhumación significa una separación de la totalidad, o un acto social de desarticulación literal, que puede haber tenido un significado más grave que la sepultura en el suelo (Buikstra y Nystrom 2015: 255). En la Laguna de los Cóndores, la presencia de los bultos en recintos previamente utilizados indica que la colocación de los antepasados en espacios privados posiblemente constituyó un acto político (Wild et al. 2007; Buikstra y Nystrom 2015). También indica que sirvió para legitimar a los invasores al representarlos como antepasados (Gose 2008). Por otro lado, la práctica de quitar a los antepasados también forma parte de una tradición que se extendía hasta la antigüedad en los Andes. Otra posibilidad es que los entierros o bultos fueran enterrados como parte de las prácticas sociales en la reconstitución de las casas, y se puede indicar que no todos los muertos eran destinados a entierros en espacios visibles al público. Los entierros en casa no solo se ven en Purun Llacta, sino también en otros sitios de Chachapoyas (Morales Gamarra et al. 2002; Schjellerup 2005; Nystrom et al. 2010). Lo que sí se puede afirmar es que la práctica de enterrar a los antepasados en chullpa y en las casas continuó hasta la época colonial (Duviols 1986). Las prácticas funerarias y el uso de los espacios públicos y privados para el tratamiento de los muertos en Purun Llacta de Soloco se mantuvieron durante las épocas inka y colonial temprana.

El uso del espacio público en el sector bajo de Purun Llacta manifiesta otra forma de relación con la comunidad, y fue fuertemente influenciado por las ideas de planificación cívica inka y española. Este distrito parece haber sido desarrollado durante el Horizonte Tardío y modificado a principios de la época colonial española. En general, los edificios de este sector parecen haber sido construidos con una preocupación por los espacios cívicos. Por ejemplo, varias estructuras rectangulares grandes y una plaza pequeña fueron construidas con orientación hacia el Qhapaq Nan, el 


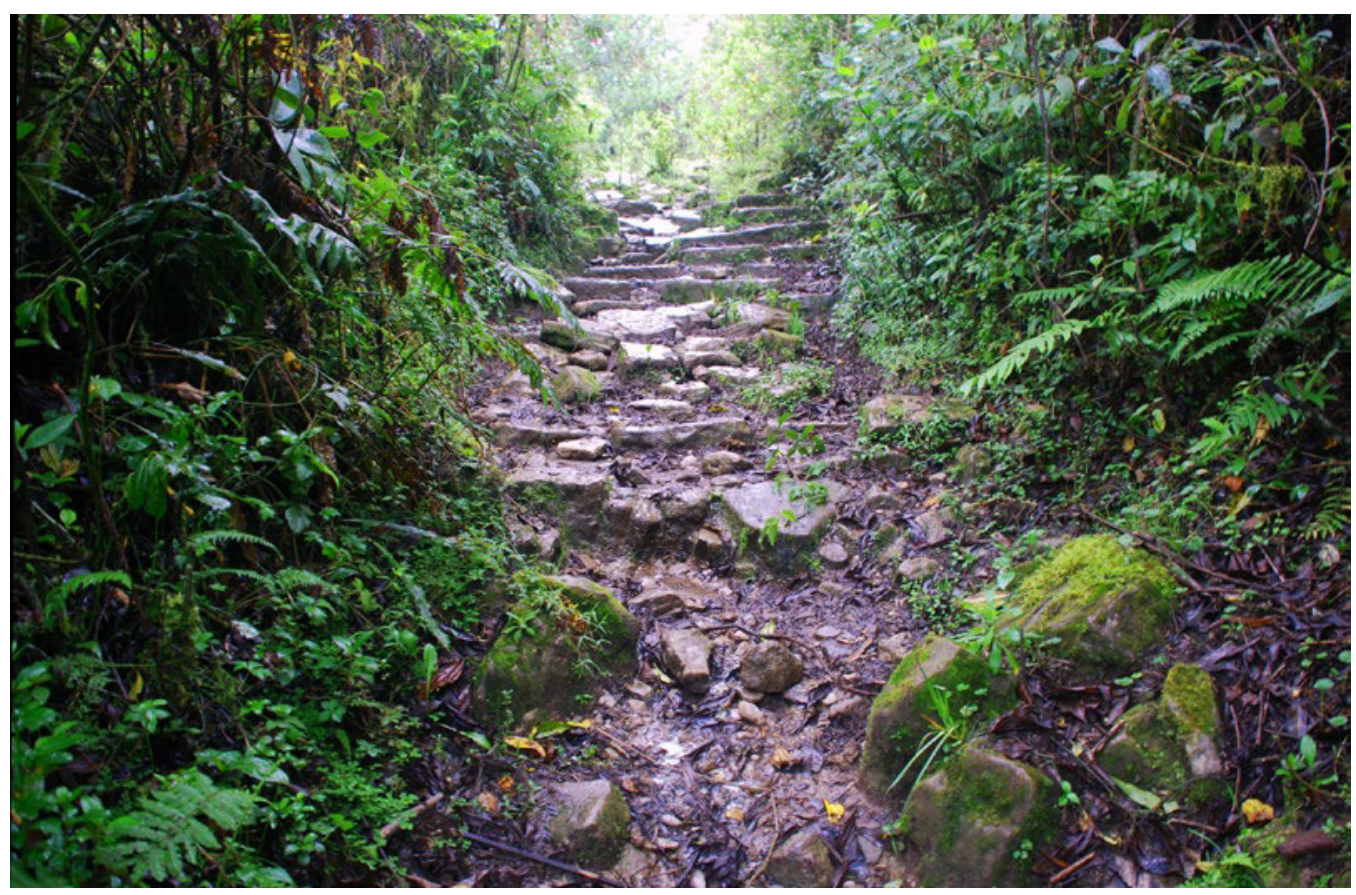

Figura 11. Tramo del Qhapaq Nan que pasa por el centro del Purun Llacta de Soloco (foto por J. M. Crandall).

cual divide el centro del sitio en dos partes (Fig. 11). Una gran estructura rectangular (Est. \#37) construida al lado del camino refleja la mejor calidad arquitectónica del Sector A. Su posición y el estilo arquitectónico sugieren que posiblemente puede haber sido un tampu. En el otro lado de la carretera, se seleccionó para la excavación una gran estructura rectangular de 8 por 6 metros (Estructura \#88), porque representa la única estructura en Purun Llacta que se asemeja al estilo de arquitectura inka vernácula de accesos dobles (Nair y Protzen 2015). La excavación de esta estructura (Fig. 12) reveló una serie de pisos bien definidos, construidos de arcilla amarilla y piedra caliza, con un grosor de 10 centímetros. La presencia de huecos de vigas de soporte a través del eje central de la estructura también indica su carácter como construcción de estilo vernácula inka. Las excavaciones en el nivel más bajo del piso revelaron un entierro de un solo adulto joven con señales de artritis. El entierro contenía la ofrenda de un pequeño aríbalo que había sido disturbado por construcciones posteriores (Fig. 13). Cerámicas de estilo inka aparecen en todo Purun Llacta, aunque en cantidades relativamente bajas, y la colocación de un aríbalo policromado indica que la distribución de la cerámica inka vinculó a los individuos de la comunidad con los mecanismos imperiales de intercambio.

No se puede identificar fácilmente a agrupaciones lineales o aglutinadas entre las casas de este sector, y es evidente que la ubicación de estructuras fue determinada según una manera distinta durante la época inca-colonial. Muchas estructuras se organizan en relación con el Qhapaq Nan y las vías internas del sitio. El plan cívico de este sector indica que los grupos del patio resultaron de algún tipo de planificación centralizada. Por ejemplo, la Estructura \#26 es un edificio con forma de «D», el cual fue construido sobre una plataforma de 1,2 metros de altura compartida con dos casas vecinas. Estas estructuras adyacentes forman parte de una ruta que se extiende hasta la plaza central. Se recuperaron herramientas de hueso, chaquiras de hueso con diseños de rombo y fragmentos de cobre inka en el piso más bajo. La superficie de este piso fue intensamente quemada y estaba asociada con huesos de camélidos (NMI=2), lo cual posiblemente implica que un evento de festejo ocurrió en el momento de la construcción de la casa. Artefactos coloniales fueron recuperados 


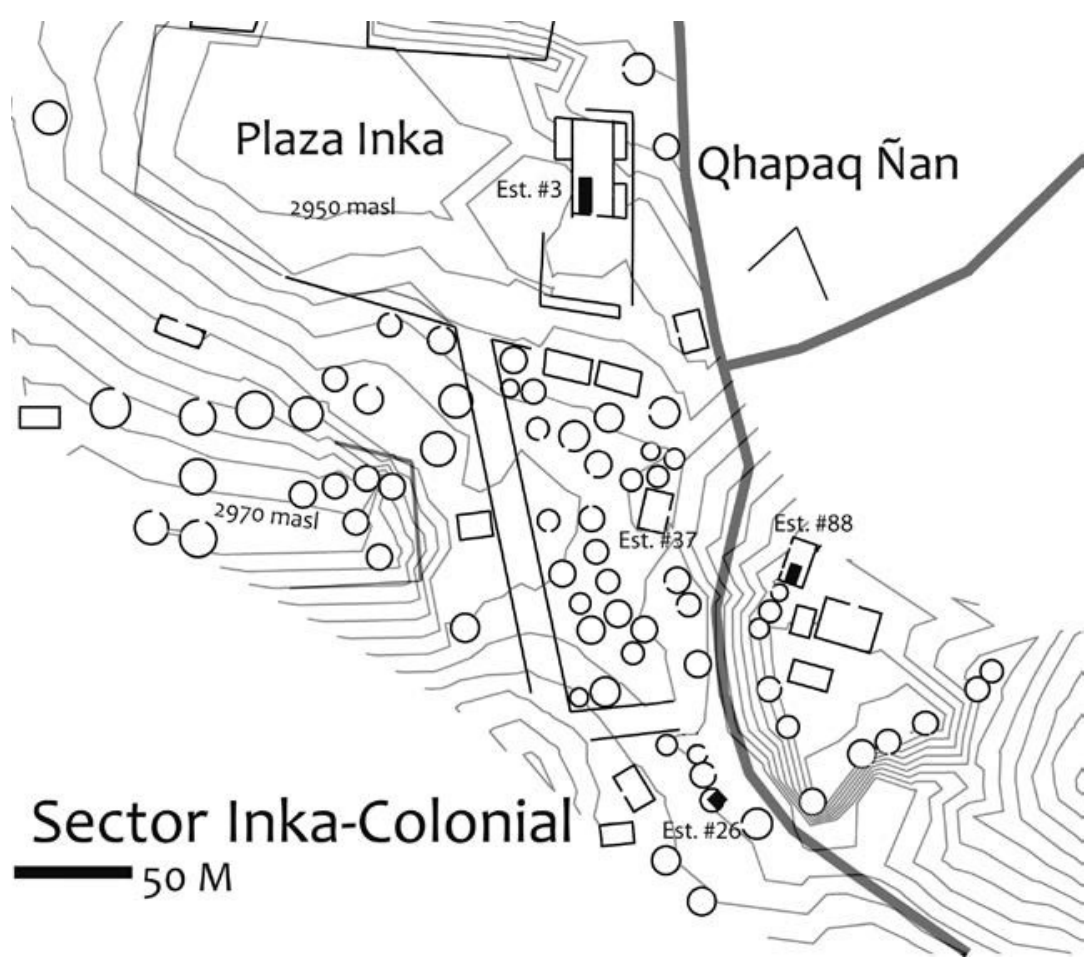

Figura 12. Unidades de excavación en el sector Inka-colonial (dibujo por J. M. Crandall).

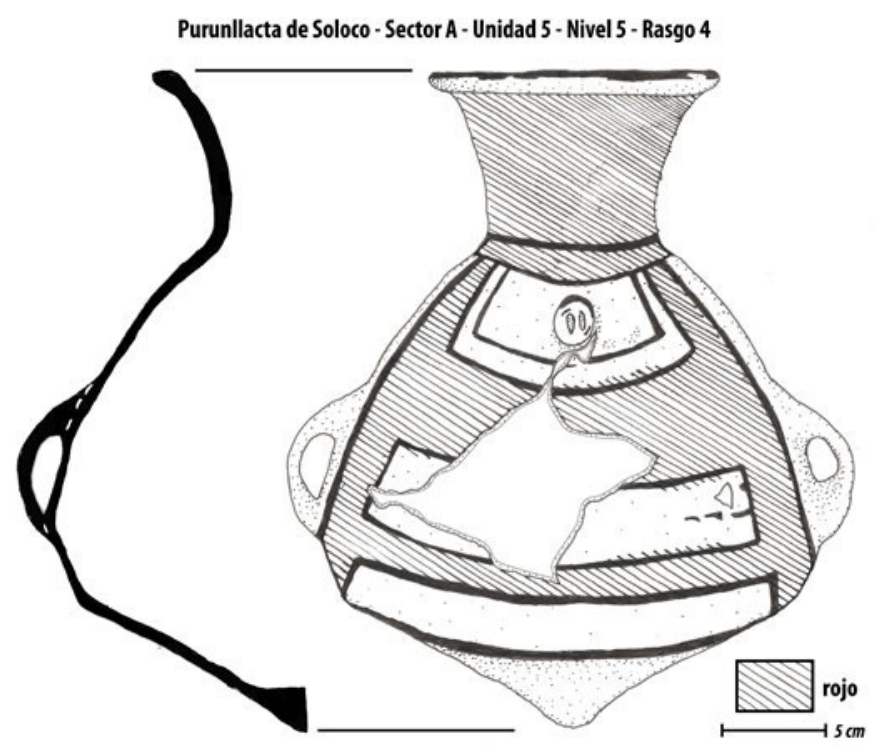

Figura 13. Aribalo Inka encontrado con un entierro humano en la Est. \#88 (dibujo por J. M. Crandall). 
de la última fase de ocupación e incluyeron una chaquira Nueva Cádiz del mismo estilo que las recuperadas en la Estructura \#98.

En comparación con el Sector B, la organización de la comunidad en el Sector A se distingue por la mayor cantidad de espacio y por la predominancia de elementos de construcción cívica (Fig. 3). En el centro del Sector A, se construyó una larga vereda de 74 metros como una entrada al lado sur de la plaza. La plaza está delimitada por terrazas de contención hacia el norte, el sur y el este. En total, tiene una superficie de 71 por 48 metros. Los ushnus frecuentemente se encuentran al centro de las plazas inkas, y se han registrado en muchos sitios de los Andes peruanos nororientales (Coello 2004; Schjellerup 2015). Es posible que también haya existido un ushnu en Purun Llacta. Sin embargo, la ganadería y la agricultura han perturbado la zona, y solo un montículo bajo de piedra caliza queda de un elemento arquitectónico no identificable en el centro de la plaza. Tres estructuras rectangulares en el sur de la plaza posiblemente representan unas kallankas, y la plataforma al norte de la plaza contiene seis estructuras rectangulares entrelazadas que probablemente fueron qollqas. En el norte del Sector A hay una plataforma enorme (74 por 50 metros) que se alza 10 metros sobre el sector colonial. La plataforma incorporó un gran afloramiento de roca madre, al cual fue agregada piedra caliza para nivelarla y así formar una gran terraza, cuya fecha de modificación ha quedado sin determinar. Con la excepción de tres estructuras, una depresión en el centro y las chullpas en el exterior, la plataforma es en gran medida un espacio abierto desprovisto de rasgos.

Si bien es evidente que la mayor parte del sitio fue ocupada durante el período colonial temprano, la arquitectura de obvio origen colonial se limita a una plaza (38 por 20 metros) rodeada por ocho estructuras rectangulares, y a una enorme estructura (28 por 20 metros) en el lado de la plaza inka. Es muy probable que el enorme edificio en la plaza central (Estructura \#3) sea una capilla de mediados del siglo XVI. Esta estructura se compone de una gran sala central con entrada al sur y un altar en el extremo norte. Tres habitaciones colindan con la estructura y parecen haber sido añadidas en un momento posterior (Fig. 14). Cada una de estas salas auxiliares se abre al exterior de la estructura y no al gran espacio interior. Por desgracia, el interior estaba muy limpio y solo unos pequeños fragmentos de cerámica diagnóstica de la época colonial fueron recuperados del piso superior.

Es probable que la estructura fuera utilizada solo durante un período breve. Sin embargo, durante este tiempo cuatro entierros humanos fueron colocados cerca de la entrada de la sala central. Aunque estos entierros estaban mal conservados, uno era de un adulto joven que había sido colocado en el suelo con los brazos cruzados en el pecho y que tenía características craneales morfológicas distintas de los otros entierros encontrados en Purun Llacta (M. Toyne, comunicación personal). La estructura comparte varias características con la iglesia colonial construida en la Jalca Grande en 1540 d.C., lo cual parece apoyar la interpretación de que fue una capilla temprana. Por ejemplo, ambos tienen largas salas centrales con pequeñas habitaciones contiguas que se abren hacia el exterior. Además, ambas tienen una pared baja que circunda la estructura, posiblemente sirviendo como plaza externa. Esta situación también reproduce un patrón ampliamente distribuido en el Perú: que los franciscanos establecieron sus primeras doctrinas en centros administrativos inkas (Wernke 2012: 168). Una investigación reciente también sugiere que la colocación de los entierros en las primeras iglesias coloniales de Sudamérica fue más común de lo que se pensaba (Zucchi 2006). Durante este período varias órdenes eclesiásticas, entre ellas las órdenes de la Merced, San Agustín y San Francisco, llevaron a cabo la fundación de doctrinas en el este del Amazonas (Armas Medina 1953). Muchas de ellas fueron abandonadas o reubicadas cuando las comunidades de la zona fueron reducidas en la década de 1580 .

Además de la adaptación de la plaza central, los ocupantes españoles iniciaron la construcción de una plaza rectangular más pequeńa que mide 38 por 20 metros, al centro de la parte norte de la plaza inka (Figs. 15 y 16). La preocupación con el espacio compartido probablemente fue uno de los principales conceptos de planificación que influyó en la construcción de esta plaza. Las siete estructuras rectangulares y una estructura en forma de «D" son en promedio más grandes que las otras estructuras del sitio, y todas tienen cornisas salientes en la base. Las excavaciones en la 


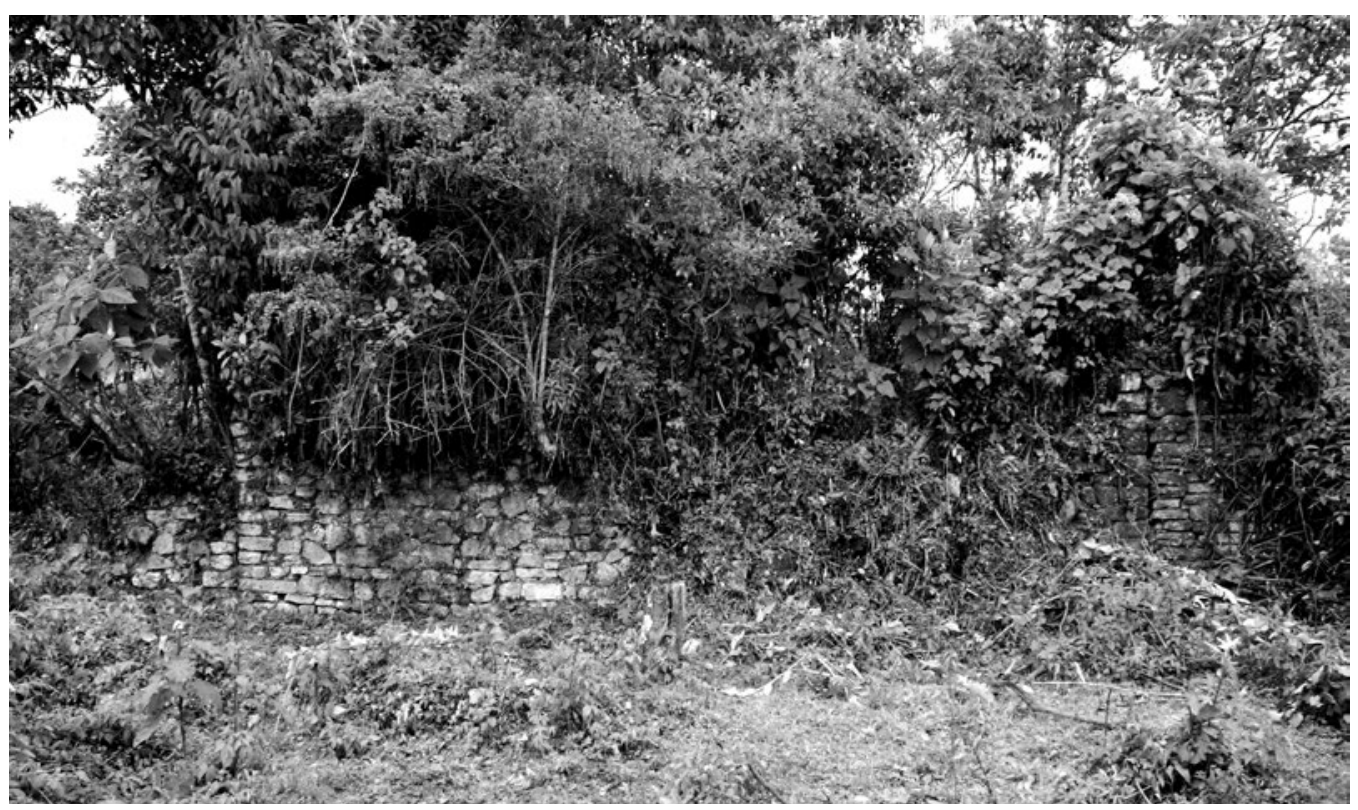

Figura 14. El lado norte de la Est. \#3, probablemente una capilla del siglo XVI (foto por J. M. Crandall).

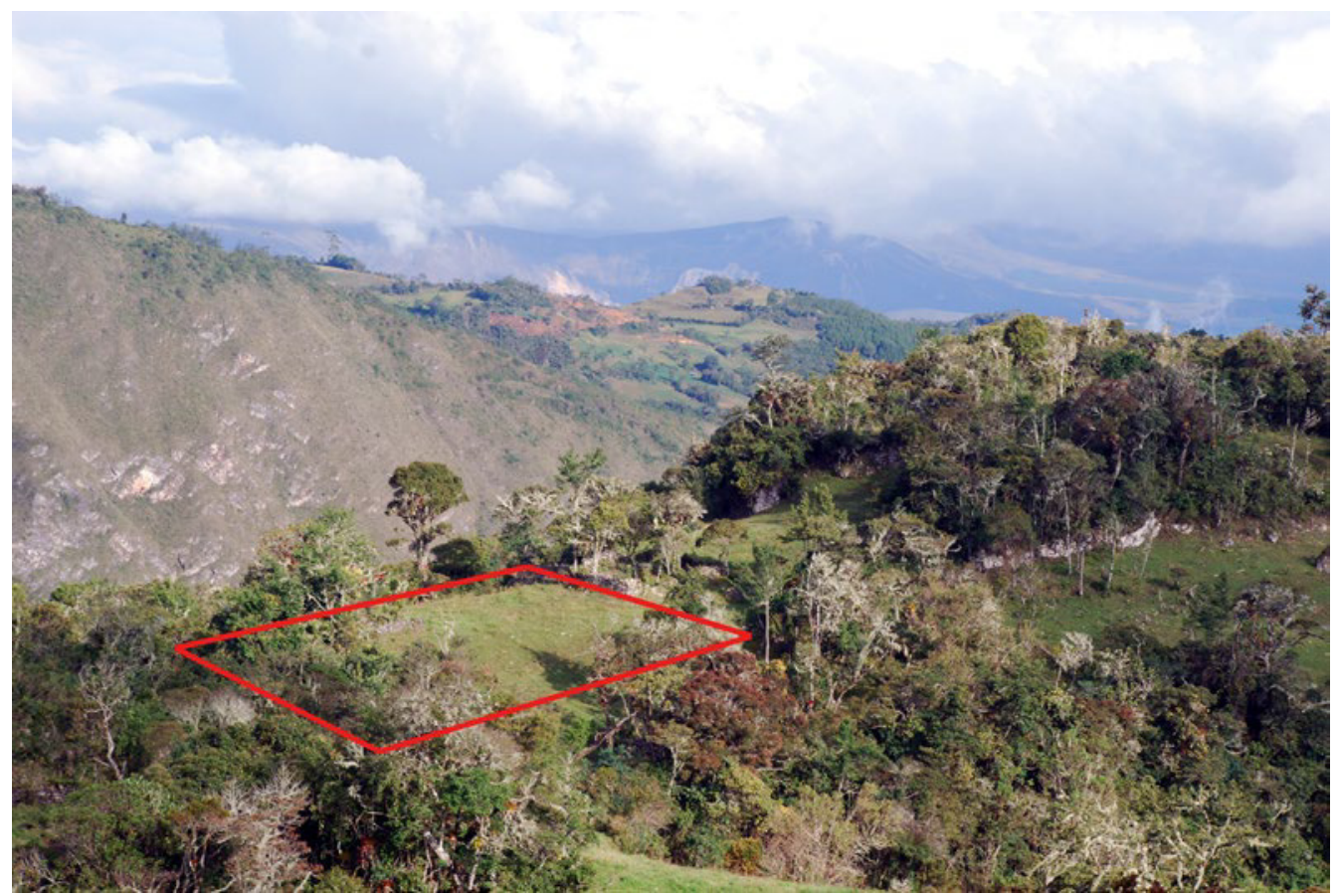

Figura 15. Plaza colonial en Sector A (oeste) de Purun Llacta de Soloco (foto por J. M. Crandall). 


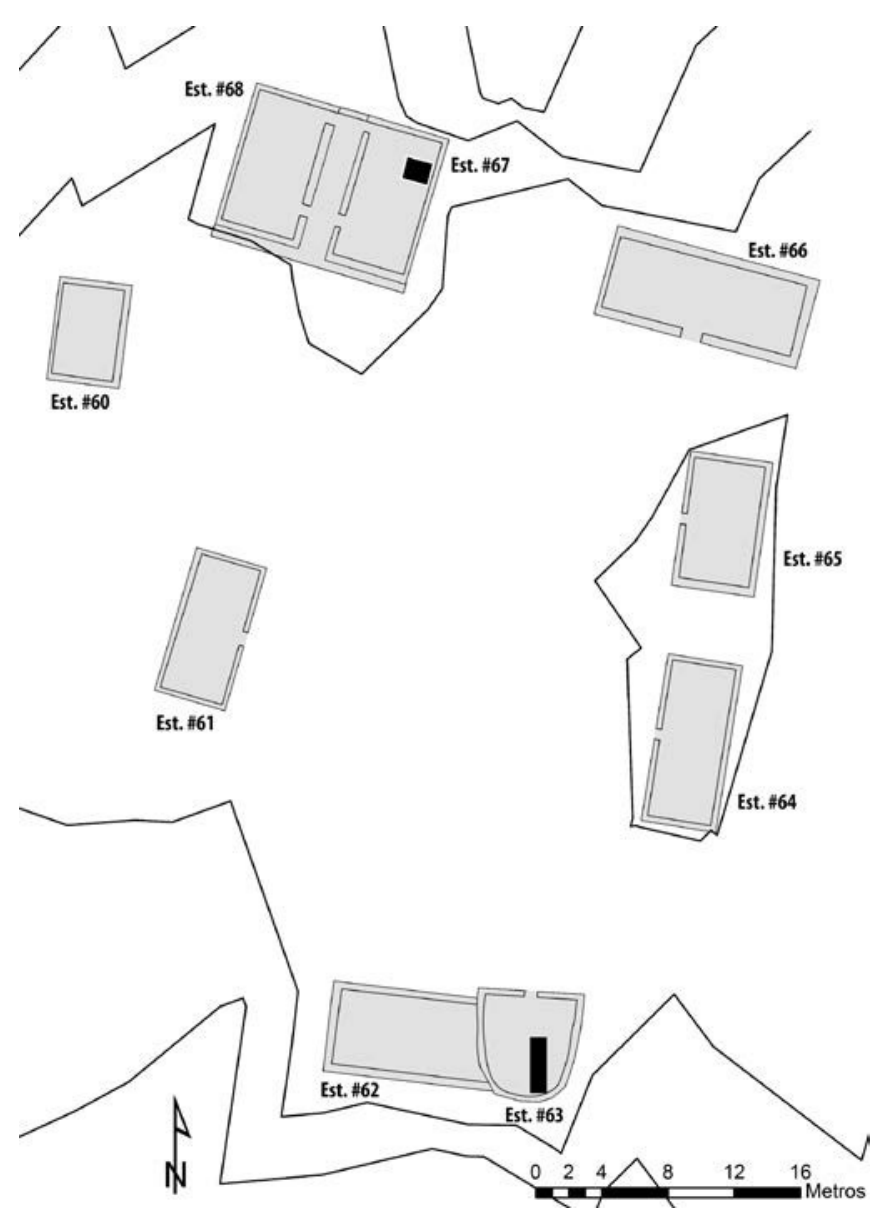

Figura 16. Croquis de la plaza colonial en Sector A de Purun Llacta de Soloco (dibujo por J. M. Crandall).

en el centro del sector Chachapoya. A lo largo del Período Intermedio Tardío, la comunidad se desarrolló gradualmente hacia el exterior, probablemente guiada por normas de relaciones sociales que gobernaban el uso y desarrollo del espacio social hacia el futuro. En algún momento durante el Horizonte Tardío (después la década de 1470), el sitio fue convertido en un centro administrativo inka y expandido para incorporar los aspectos formales de un espacio cívico. Los episodios de construcción nueva en la comunidad todavía pueden haber sido guiados por las lógicas sociales chachapoya, tales como la organización de casas o la exposición de antepasados particulares, pero fueron adaptados al nuevo esquema de superposición de una economía extractiva imperial sobre las relaciones locales anteriores. Purun Llacta continuó siendo ocupado a principios del período colonial español, y posiblemente fue el sitio de una doctrina temprana que fue abandonada cuando se realizó el proceso de reducción en esta región en 1583. Es probable que los miembros de la comunidad todavía utilizaran el sitio esporádicamente después de la reducción. La expresión espacial de la vida comunitaria en Purun Llacta se vio afectada por una serie de relaciones ideológicas y materiales. Para comprender estas relaciones hago uso de un modelo de desarrollo comunitario que pretende comprender la constitución social de la comunidad en términos de las relaciones arquitectónicas. 


\section{Metodología del análisis espacial}

Uno de los objetivos del proyecto fue examinar los sitios arqueológicos de la región del río Sonche a fin de identificar el desarrollo comunitario a nivel regional, así como cambios internos en los sitios que correspondieran a la presión política externa. La cuestión de los aspectos relacionales del espacio en las sociedades ha constituido un tema de interés para geógrafos, antropólogos y otros (Hillier y Hanson 1984). Lógicas culturales del espacio son íntimamente integradas en el tejido y la constitución de las relaciones sociales que estructuran las divisiones en las casas (Bourdieu 1970; Heckenberger 2005: 255-290), las que organizan los espacios públicos (Low 1995; Swenson 2014) y definen los estados (Navaro-Yashin 2012; Weizman 2007). Aquí me ocupo de la cuestión de cómo los sistemas imperiales impactaron la expresión social del espacio durante los siglos XV y XVI.

El estudio de Purun Llacta de Soloco tuvo el propósito de definir los límites del espacio en términos de la totalidad del entorno construido. Esta investigación se centró en la presencia o ausencia de construcciones arquitectónicas y en la extensión de características arquitectónicas particulares, así como en los cambios a gran escala de los espacios de la comunidad. En total, se han identificado 264 estructuras en dos sectores del sitio. La arquitectura de Purun Llacta es diversa e incluye hasta tres formas estructurales (Tabla 1) que comparten una uniformidad en el tamaño, la forma y las técnicas de construcción dentro de cada una de estas categorías.

\begin{tabular}{lcccccc}
\hline Estilo de arquitectura & Sector A & \% de Sector & \% de Total & Sector B & \% de Sector & \% de Total \\
\hline Circular & 54 & 56.9 & 20.5 & 151 & 89.4 & 57.2 \\
Rectangular & 34 & 35.8 & 12.9 & 1 & 0.6 & 0.4 \\
Forma de "D" & 7 & 7.3 & 2.6 & 17 & 10 & 6.4 \\
\hline Total (N=264) & 95 & 100 & 36 & 169 & 100 & 64 \\
\hline
\end{tabular}

Tabla 1. Formas y ubicaciones de las estructuras que se encontraron en el reconocimiento de Purun Llacta de Soloco

Durante el mapeo del sitio se prestó especial atención a la forma de los elementos arquitectónicos. Para las casas circulares, fueron registrados los diámetros internos y el espesor del muro con el fin de establecer las dimensiones exactas. Se realizó un tratamiento parecido para las estructuras en forma de «D». Para las estructuras rectangulares, fueron tomados los puntos de las esquinas internas y externas, además de los puntos centrales de la arquitectura. Las medidas exactas fueron importantes para establecer el área de los espacios delineados por la distancia entre los elementos arquitectónicos, medidas que fueron utilizadas para construir los polígonos utilizados en el análisis espacial.

Este análisis espacial considera al entorno construido como un aspecto de la agencia de la comunidad, en el sentido de que las decisiones futuras se guían por las estructuras sociales y físicas (sensu Lefebvre 1991, Soja 1980). En Purun Llacta de Soloco, el desarrollo comunitario se expresó a través de normas sociales que regían las asociaciones entre los miembros de la población y las obligaciones formadas a través de conceptos de afinidad. Además, las obras públicas, que muestran una planificación urbana de arriba hacia abajo, probablemente influyeron y afirmaron las cosmologías políticas o religiosas que guiaron la constitución y la utilización de esos espacios. Sin dejar de lado los procesos históricos, las diferencias en los enfoques del ordenamiento del territorio que se describen a continuación pueden haber resultado de las cosmologías sociales que regían el uso del espacio. En efecto, el espacio representa otro dominio de la práctica cuyo estudio requiere el reconocimiento de que las diferencias entre comunidades sociales y al interior de ellas son a menudo influidas por los modos de producción y las cosmologías que impactan la producción. 


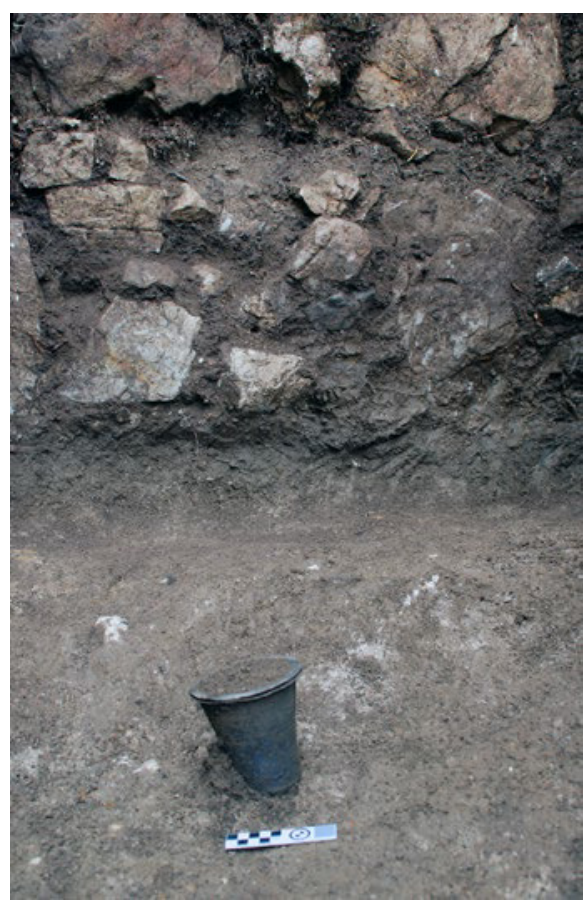

Figura 17. Dos aquillas de plata colonial descubiertas en un contexto ritual al lado de la plaza colonial foto por J. M. Crandall).

Se utilizaron datos de la prospección y de SIG para evaluar la hipótesis de que la arquitectura pública de Purun Llacta exhibe signos de planificación de arriba hacia abajo (a través de las estructuras y las plazas públicas) que podrían haber diferido de modo significativo de otras formas de arquitectura como casas, terrazas, etc. Los puntos de datos se clasificaron en casas, terrazas, estructuras mortuorias, estructuras públicas y plazas públicas o de usos múltiples. Luego se utilizó ArcGIS ${ }^{9} 10.3$ para construir polígonos Thiessen que identifican el área del espacio abarcado por estas categorías. Según esta metodología ${ }^{10}$, si las áreas entre los espacios se distinguen mucho, entonces puede ser que la separación entre los espacios de uso fue significativa y refleje la planificación organizada a nivel comunitario.

Si bien esta forma de análisis se limita a la comprensión de la organización del sitio en el momento de su abandono, es útil para realizar una comparación interna de las características producidas tras el desarrollo de un sitio. Los resultados consisten en la identificación de las «zonas calientes» y «zonas frías», las cuales están delimitadas de acuerdo a la distancia total entre cualquier estructura arquitectónica construida dentro de los límites del sitio. En efecto, la presencia de áreas «calientes» significa que hay una separación estadísticamente significativa de espacio entre dos elementos arquitectónicos (por ejemplo, casas) cuando se considera la distancia entre toda la arquitectura del sitio. Esto puede indicar que la construcción de la arquitectura en estas áreas se guió por la intención de segregarla de los espacios públicos.

En Purun Llacta, hay un grado del 95\% de confianza de que las áreas cubiertas por tres de las cuatro plazas están distanciadas de la otra arquitectura de la comunidad por grados de separación estadísticamente significativos (Fig. 18). Es más, estas son las únicas áreas dentro de los límites del sitio que muestran un grado estadísticamente significativo de separación de otra arquitectura, con la excepción de dos chullpas colocadas en la periferia occidental de la comunidad y una hilera de casas que bordean la plaza inka-colonial. El grado de separación entre las estructuras construidas en el centro - que incluyen la plaza inka, la plaza colonial, la plataforma en el Sector A-, y los espacios de vivienda como las casas y las terrazas puede indicar que la construcción de la arquitectura doméstica en la comunidad se llevó a cabo con una preocupación en la segregación de los espacios cívicos construidos durante las ocupaciones inka y española. 


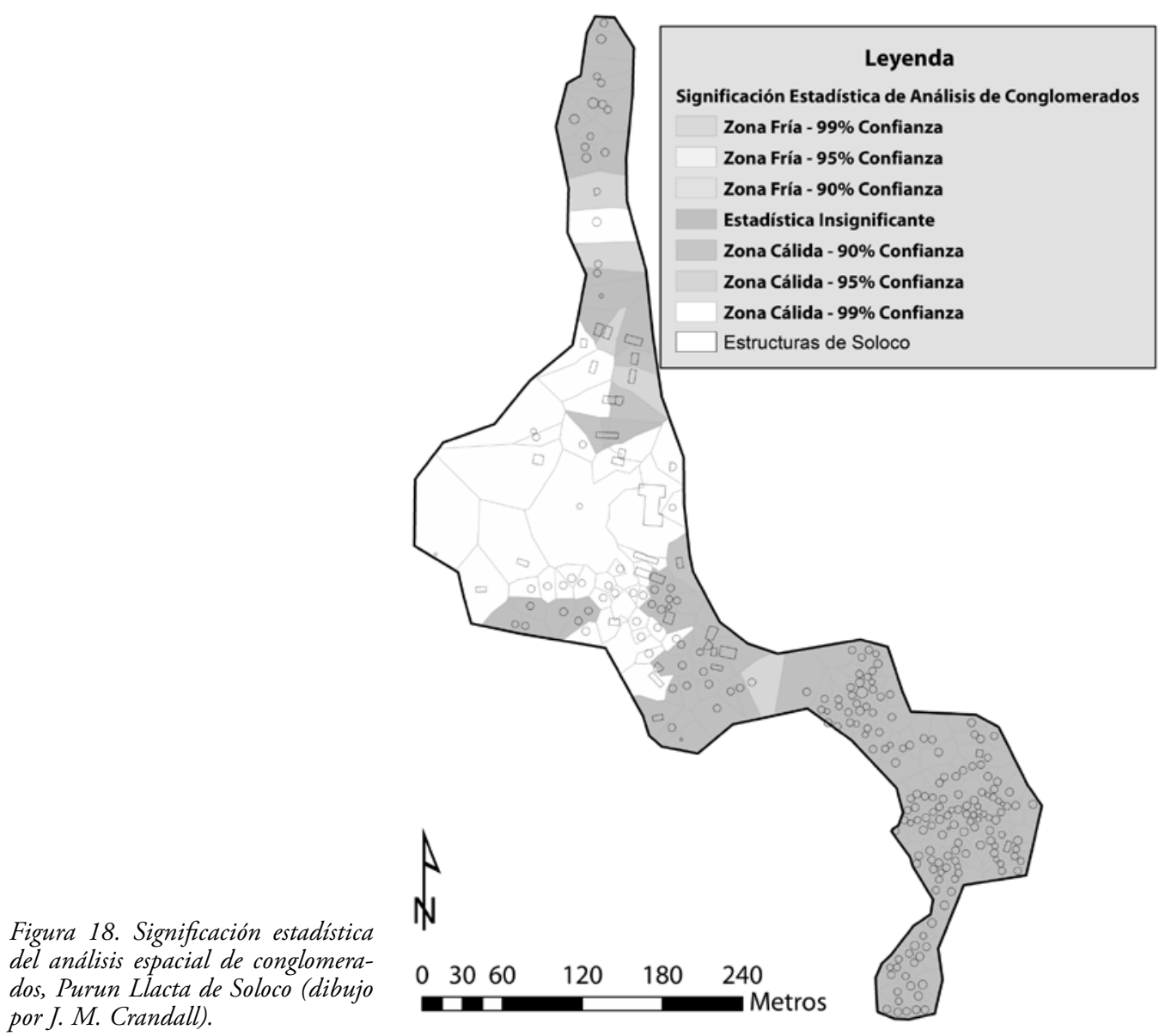

\section{Discusión}

Resúmenes recientes del período colonial español han enfatizado la continuidad de las instituciones sociales. Las estrategias españolas de gobierno, incluso la centralización de las poblaciones, aseguraron que los modos sociales, las instituciones laborales y la reciprocidad tributaria del sistema inka se mantuvieran en el período colonial temprano (Wernke 2012). La manipulación que hicieron los incas del espacio sirvió para reproducir el estado imperial a través de las acciones sociales que legitimaban su autoridad (Kosiba y Blanco 2013). El proceso de la construcción del territorio inka puede ser discutido en términos de la justificación ideológica que rige la producción social. Por ejemplo, la redistribución fue uno de los elementos fundamentales de la economía del estado inka, la cual permitió el autoabastecimiento de las cadenas de fuerza de trabajo que hicieron posible su expansión (Murra 1980, 1982, 1985; también D’Altroy y Earle 1985; Stanish y Coben 2013). Como resultado, las comunidades reprodujeron estos aparatos sociales a través de la construcción de carreteras, plazas, qollqas, kallankas, usnus y otras formas de arquitectura que sirvieron para ordenar las obligaciones laborales sociales de los curacas locales y del Estado.

La reconstitución del espacio en la región de Chachapoyas parece un esfuerzo abortado cuando se la ve a través del lente de la historia. Nuevas formas de arquitectura fueron introducidas en los sitios administrativos inkas, mientras la producción de la arquitectura chachapoya y otros materiales culturales no sufrieron una transformación radical. Estos esfuerzos fueron realizados por los inkas para transformar la región mediante el establecimiento de comunidades planificadas como 
Cochabamba, que fueron representativos del orden social inkaico (Schjellerup 1984). En general, la práctica de crear un nuevo orden parece haber estado limitada a la periferia de las comunidades chachapoya que ya existían. Otros centros inkas del norte del Tawantinsuyu, como Ingapirca, parecen haber sido re-estructurados en torno a los espacios religiosos después de su supresión durante la conquista inka (Hyslop 1990: 263-264). Estas prácticas pueden haber tenido lugar en los centros chachapoyas como Kuélap (Narváez 1996; Ruiz Estrada 2009). Sin embargo, los administradores inkas pudieron haber mirado hacia los límites periféricos de las comunidades para desarrollar ideas cívicas que contrastaban con los modos tradicionales de producción y de expansión de las comunidades. La evidencia encontrada en otros centros administrativos periféricos de los inkas sugiere que su dominio reforzó los modos preexistentes de obligaciones verticales y que las instalaciones inkas desempeñaron un papel mínimo en el cambio de las economías políticas locales (Schreiber 1993; Acuto 2010; Alconini 2010). En su mayor parte, las comunidades mixtas de Chachapoyas se organizaron en torno a los modelos tradicionales de modos de reproducción social fundamentados en la casa. La plaza inka en Purun Llacta de Soloco fue construida en el mejor terreno, y la arquitectura fue posteriormente planificada o reutilizada en relación con este monumento central. Durante la época inka, las casas, las vías internas de tránsito y otras estructuras fueron construidas con una preocupación relacional con respecto al espacio de la plaza y del Qhapaq Nan.

La construcción de los espacios públicos también puede haber reorientado el abastecimiento y las prácticas redistributivas comunitarias. Por ejemplo, la ofrenda ritual de las aquillas en el Estructura \#63 y la evidencia de las prácticas rituales en Monte Viudo (Guengerich 2014a) sugieren que los rituales ocurrieron dentro del hogar, o al menos en las estructuras especializadas que se parecían a las casas. Sin embargo, la evidencia de camélidos quemados y de otros huesos de mamíferos distribuidos libremente en los pisos más bajos del Estructura \#26 y del Estructura \#98 indica que los eventos de festejo probablemente tuvieron lugar dentro de los hogares y que quizás estuvieron asociados a las obligaciones comunitarias para la construcción de las casas. Pero la evidencia arqueológica de muchos sitios inkas sugiere que las plazas fueron utilizadas como espacios religiosos y para presentaciones públicas que tenían como propósito aprovisionar al estado inka (Bauer y Stanish 2001, Dillehay 2003, Morris 2004: 308-310; Acuto et al. 2012). Un examen de las pircas, o muros colapsados, creados por los ganaderos locales en la plaza inka de Purun Llacta confirma que había una gran concentración de cerámica en todo este espacio abierto. Un cambio en la ubicación de las actividades públicas - en la casa y en los espacios cívicos - puede haber significado que la reglamentación de las obligaciones laborales pasó a formar parte de las actividades supervisadas por los administradores inkas.

El plan de reasentamiento forzado del virrey Toledo se promulgó mucho más rápidamente en el sur que en el norte del Perú (Gade y Escobar 1982). Como resultado, los nuevos conceptos de orden social pueden haber influido en la arquitectura chachapoya de las comunidades del norte antes de dispersarse en las comunidades reasentadas. Por ejemplo, los decretos que establecían que las comunidades se cuadricularan y que las casas de los curacas fueran más grandes que las otras casas de las comunidades (ibid: 434) pueden haber influido en el diseño de la plaza colonial y la arquitectura circundante en Purun Llacta. Al mismo tiempo, las capillas coloniales tempranas generalmente fueron establecidas en lugares donde era posible aprovechar los espacios públicos de los inkas, como plazas vacías (v.g., Jennings 2003: 450; Topic y Topic 1993: 24; Wernke 2012: 168). Sin proponérselo, la reconfiguración del espacio en Purun Llacta durante el período colonial español puede haber cambiado el significado de la plaza dentro de las prácticas comunitarias. La plaza probablemente se convirtió en un espacio utilizado por las autoridades españolas de una manera parecida al uso hecho por los inkas para promulgar actividades públicas. Los primeros años de la conquista espańola interrumpieron la soberanía inka, pero a la vez los líderes locales probablemente gozaron de cierto nivel de autoridad política, que limitaba el poder de los encomenderos para explotar el trabajo de las poblaciones andinas (Stern 1993; Mumford 2012).

A pesar de la alianza de los guerreros chachapoyas con los españoles en la eliminación del dominio inka, es probable que haya existido un período significativo en que la soberanía directa española fue 
ambigua para los chachapoya y otras poblaciones andinas (Lamana 2008). Por ejemplo, la mayoría de los habitantes de la región de Cheto no estaba bajo la influencia del catolicismo español en 1595, a pesar de la voluntad política de las órdenes eclesiásticas regionales (Mogrovejo en Benito Rodríguez 2006). Se cuenta que el anexo de Soloco y las comunidades vecinas fueron curatos de Cheto, o estaban bajo su autoridad eclesiástica (Martínez de Compañón 1792). Esto indica que una capilla temprana en Purun Llacta probablemente carecía de un sacerdote con residencia permanente, siendo visitada solo de vez en cuando. Mientras los encomenderos sin duda habrían explotado la fuerza de trabajo local tanto como les resultó posible, la explotación fue limitada por las relaciones con los curacas locales (Cole 1985). Se debe tener en cuenta que comunidades como Purun Llacta de Soloco probablemente mantuvieron cierto grado de autonomía política durante los primeros cuarenta y cinco años de la conquista espańola, hasta que su pueblo se vio obligado a trasladarse en el programa de la reducción, cuando los encomenderos tenían mayores mecanismos estructurales para explotar su mano de obra.

\section{Conclusión}

Los sistemas ideológicos y las prácticas coloniales asociadas con la fuerza de trabajo bajo el régimen inkaico y español impactaron de manera radical las comunidades chachapoya. Los inkas promulgaron un programa de incorporación que simultáneamente solidificó las relaciones vigentes entre los chachapoya, a la vez que cambiaron la capacidad de los individuos de viajar entre las comunidades del imperio. Instituyeron nuevos modos de producción ideológica en forma de espacios públicos donde sería posible realizar actividades que apoyaran la ideología del Estado. Estos espacios se convirtieron en foco de la vida cívica en algunas comunidades chachapoya durante el Horizonte Tardío. Los españoles continuaron la práctica de incorporación en la época colonial temprana e integraron los espacios inkas, como las plazas, en su plan para promover la explotación de la mano de obra y organizar la vida cívica de los chachapoya en torno a ideales españoles de civitas. Los encomenderos que llegaron durante el siglo XVI frecuentemente se situaron a sí mismos al centro de estos nuevos espacios comunitarios. A través de un cuidadoso examen del desarrollo de las comunidades chachapoya podemos ver cómo la reorientación de los espacios cívicos hubiera impactado las prácticas sociales dentro de las comunidades. Con la consideración de preocupaciones históricas, he tratado de mostrar que el análisis espacial cuidadoso puede identificar áreas de comunidades que probablemente se vieron afectadas por la planificación cívica organizada. Los métodos de análisis espacial se pueden aplicar a otros sitios chachapoya para ayudar a identificar los cambios diacrónicos en la estructura comunitaria. El desarrollo y posterior abandono de Purun Llacta de Soloco es representativo de los cambios de largo plazo que afectaron a varias regiones de los Andes nororientales bajo los múltiples regímenes coloniales.

\section{Agradecimientos}

Quiero agradecer a los editores, Anna Guengerich y Warren Church, por su invitación a contribuir en este volumen. Las excavaciones realizadas entre el 2014 y el 2015 fueron apoyadas por becas del Ruegamer Fundación y de la Escuela de Posgrado, el Centro de Estudios Latinoamericanos y el Departamento de Antropología de la Universidad de Florida. Quisiera agradecer en particular a mi colega y co-director Lorenzo Risco Patiño. Este proyecto no hubiera sido posible sin el apoyo de Augusto Oyuela-Caycedo, Edward Swenson, John Warner, Sally Lynch, Eyrin Chávez Chancahuana, Guidmar Chávez Llatance, Marla Toyne, Manuel Malaver Pizarro, Luis Jaime Castillo, la comunidad de Soloco, el Museo Arqueológico Nacional Brüning y el Ministerio de Cultura (Resolución N 430-2014-DGPA-VMPCIC/MC). 


\section{Notas}

${ }^{1}$ Los topónimos «Purum Llacta» $\mathrm{y}$ «Purun Llacta» se utilizan indistintamente en la literatura. Fabre (2006) y Ruiz Estrada (2004) utilizan «Purum» para Cheto y Soloco. Reichlen y Reichlen (1950: 231) solo utilizan «Soloko». He optado por utilizar «Purun», ya que representa el término comúnmente utilizado por la comunidad de Soloco.

${ }^{2}$ Con la excepción de una gran piedra tallada que representa un híbrido de un felino y de una deidad antropomorfa con motivos de serpientes, que fue descubierto en un lugar desconocido de Purun Llacta de Soloco (Lerche 1995: 48). Sin embargo, se han identificado petroglifos hasta el sur de Léon Potrero.

${ }^{3}$ La región al sureste de Cheto y Soloco incluye una ruta corta hacia Cochamal y Rodríguez de Mendoza. La altitud se reduce de 3200 a 1500 msnm en menos de 20 kilómetros. Es probable que ello representa una de las principales razones por la cual los inkas tomaron interés en este distrito. Por ejemplo, en la década de 1590 los nativos de Cheto, Olía y Timal viajaron por esta ruta para la cosecha de coca (Mogrovejo [1595] en Benito Rodriguez 2006: 124).

${ }^{4}$ También «Pipus».

${ }^{5}$ «El rrepartimiento de olia y cheto encomendado en Pedro de Vergara tiene 320 yndios tributaries y 1861 personas rreducidos en dos pueblos del mesmo nombre» [sic] (Cristóbal de Miranda 1925 [1583]: 217).

${ }^{6}$ En 1595, había al menos ocho encomenderos en el valle de Sonche.

${ }^{7}$ Los otros cinco entierros estaban demasiado fragmentados o incompletos para hacer esta afirmación.

${ }^{8}$ La única chullpa que albergaba restos humanos contenía los restos de un adulto joven.

${ }^{9}$ La herramienta Getis-Ord en ArcGIS utiliza el análisis espacial estadístico (ESRI 2010, Getis y Ord 1992) para identificar y analizar las puntuaciones puntajes $Z$ y valores $\mathrm{p}$ de todos los puntos de datos, rasgo por rasgo, y su relación con otras características. La hipótesis nula plantea que no existen niveles significativos de distancia entre las categorías funcionales de arquitectura con valores altos de la zona.

${ }^{10}$ Los polígonos Thiessen sirven como un medio para definir el área y la distancia entre puntos en el espacio. Mediante el uso de coordenadas euclidianas, estas áreas son modeladas en forma de unidades poligonales para establecer la distancia entre los espacios de uso, como por ejemplo la arquitectura delimitada. Los resultados de los polígonos Thiessen fueron recortados en asociación con la frontera geográfica del sitio. Las estadísticas globales fueron utilizadas para identificar las áreas abarcadas en el análisis estadístico. Estadísticas globales metodológicas de ArcGIS utilizan una forma de estadística inferencial que cuantifica la fuerza de las relaciones entre las variables independientes y dependientes.

\section{REFERENCIAS}

Acuto, F.

2010 Living under the imperial thumb in the northern Calchaquí Valley, Argentina, en M. Malpass y S. Alconini (eds.), Distant provinces in the Inka Empire: toward a deeper understanding of Inka imperialism, 108-150, University of Iowa Press, Iowa City.

Acuto, F., A. Troncoso y A. Ferrari

2012 Recognizing strategies for conquered territories: a case study from the Inka north Calchaquí Valley, Antiquity 86, 1141-1154. 
Alconini, $S$.

2010 Yampara households and communal evolution in the southeastern inka peripheries, en M. Malpass y S. Alconini (eds.), Distant provinces in the Inka Empire: toward a deeper understanding of Inka imperialism, 75-107, University of Iowa Press, Iowa City.

Armas Medina, F.

1953 Cristianización del Perú (1532-1600), Escuela de Estudios Hispanoamericanos, Sevilla.

Bauer, B. y C. Stanish

2001 Ritual and pilgrimage in the ancient Andes: The islands of the Sun and Moon, University of Texas Press, Austin.

Benito Rodríguez, J.A.

2006 Libro de visitas de santo Toribio Mogrovejo, 1593-1605, Fondo Editorial PUCP, Lima.

Bonavia, D.

1968 Las ruinas del Abiseo, Universidad Peruana de Ciencias y Tecnología, Lima.

Bourdieu, P.

1970 The berber house or the world reversed, Social Science Information 9(2), 151-170.

Bueno Mendoza, A. y M. Cornejo García

2009 Arqueología de la cuenca del río Guabayacu, Región San Martín, Perú, Investigaciones Sociales 13(23): $15-58$.

Buikstra, J.E. y K.C. Nystrom

2015 Ancestors and social memory: a South American example of dead body politics, en: I. Shimada y J.L. Fitzsimmons (eds.), Living with the dead in the Andes, 245-266, University of Arizona Press, Tucson.

Church, W.

1996 Prehistoric cultural development and interregional interaction in the tropical montane forests of Peru, tesis de doctorado, Yale University, New Haven.

1997 Mas allá del Gran Pajatén: conservando el Paisaje Prehispánico Pataz-Abiseo, Revista del Museo de Arqueología e Historia 7, 205-248.

Church, W. y A. von Hagen

2008 Chachapoyas: cultural development at an Andean cloud forest crossroads, en: H. Silverman y W. Isbell (eds.), Handbook of South American archaeology, 903-926, Springer, New York.

Coello, A.

2004 Yurayacu: primeras investigaciones histórico arqueológicas sobre un asentamiento inka, en: L. Alvarez (ed.), Desarrollo arqueológico costa norte del Perú, vol.2, 100-108, Sian, Trujillo.

Cole, J.A.

1985 The Potosi mita 1573-1700: compulsory indian labor in the Andes, Stanford, Stanford University Press.

Cook, A.G.

2001 Huari d-shaped structures, sacrificial offerings, and divine rulership, en: E.P. Benson y A.G. Cook (eds.), Ritual sacrifice in ancient Peru, 137-163, University of Texas Press, Austin.

Cook, N.D.

1981 Demographic collapse: Indian Peru, 1520-1620. Cambridge University Press, Cambridge.

Crandall, J.M.

2012 The eschatology of the Chachapoya: spaces of death in the northern Andes, Baessler-Archiv 60, 39-55.

Cummins, T.

2002a Forms of Andean colonial towns, free will, and marriage, en: C.L. Lyons y J.K. Papadopoulos, Archaeology of colonialism: comparative perspectives, 199-240, Getty Research Institute, Los Angeles.

2002b Toasts with the Inca: andean abstraction and colonial images on Quero Vessels, University of Michigan Press, Ann Arbor.

D'Altroy, T. y T. Earle

1985 Staple finance, wealth finance, and storage in the Inka political economy, Current Anthropology 26(2), $187-26$. 
Dillehay, T. D. (ed.)

1995 Tombs for the living: Andean mortuary practices: a symposium at Dumbarton Oaks 12th and 13th October 1991, Dumbarton Oaks Research Library and Collection, Washington, D.C.

2003 El colonialismo inka, el consumo de chicha y los festines desde una perspectiva de banquetes políticos, Boletin de Arqueología PUCP 7, 355-363.

Duviols, P.

1986 Cultura andina y represión. procesos y visitas de idolarias y hechicería, Cajatambo, Siglo XVII, Centro de Estudiós Rurales Andinos Bartolome de Las Casas, Cuzco.

\section{Epstein, L. y M. Toyne}

2016 When space is limited: a spatial exploration of a pre-Hispanic Chachapoya mortuary and ritual microlandscape, en: A.J. Osterholtz (ed.), Theoretical approaches to analysis and interpretation of commingled buman remains, 97-124, Springer International.

Espinoza Soriano, W.

1967 Los señoríos étnicos de Chachapoyas y la alianza hispano-chacha, Revista Histórica 30, 224-332.

ESRI

2010 High/Low Clustering http://help.arcgis.com/En/Arcgisdesktop/10.0/Help/index.html\#/How_High_ Low_Clustering_Getis_Ord_General_G_works/005p0000000q000000/

Fabre, $\mathrm{O}$.

2006 Contribution à l'archéologie de la région Chachapoya, Pérou, tesis de docotorado, Université Paris 4-Sorbonne, Paris.

Fabre, O., J.L. Guyot, R. Salas, M. Malaver y E. Maniero

2008 Los Chachapoya de la Región de Soloco: Chacquil, del Sitio de Hábitat a la Cueva Funeraria, Bullletin de I'Institut Français d'Études Andines 37(2), 271-292.

Fairley Jr., J.P.

2003 Geologic Water Storage in Precolumbian Peru, Latin American Antiquity 14(2), 193-206.

Francis Jr., P.

2009 The Glass Beads of the Paternostri of Venice, en: E.H. Blair, L.A. Pendleton, y P.J. Francis (eds.), The Beads of St. Catherines Island, Anthropological Papers of the American Museum of Natural History n. 89, 65-69, Washington D.C.

Gade, D.W. y M. Escobar

1982 Village Settlement and the Colonial Legacy in Southern Peru, Geographical Review 72(4), 430-449.

Getis, A. y J. Ord

1992 The Analysis of Spatial Association by use of Distance Statistics, Geographical Analysis 24, 189-206.

Gose, P.

2008 Invaders as Ancestors: On the Intercultural Making and Unmaking of Spanish Colonialism in the Andes, University of Toronto Press, Toronto.

Guengerich, A.

2014a Monte Viudo: Residential Architecture and the Everyday Production of Space in a Chachapoya Community, tesis de doctorado, University of Chicago, Chicago.

2014b The Architect's Signature: The Social Production of Residential Landscape at Monte Viudo, Chachapoyas, Peru, Journal of Anthropological Archaeology 34, 1-16.

2015 Settlement Organization and Architecture in Late Intermediate Period Chachapoyas, Northeastern Peru, Latin American Antiquity 26(3), 362-381.

Guillén. $S$.

2000 Evaluación y delimitación del sitio arqueológico Llaqtacocha, informe final, Instituto Nacional de Cultura, Lima.

Heckenberger, M.J.

2005 The ecology of power: culture, place, and personhood in the southern Amazon, A.D. 1000-2000, Routledge, New York. 
Hillier, B. y J. Hanson

1984 The social logic of space, Cambridge University Press, Cambridge.

Hyslop, J.

1990 Inka settlement planning, University of Texas Press, Austin.

Jennings, J.

2003 Inca imperialism, ritual change, and cosmological continuity in the Cotahuasi Valley of Peru, Journal of Anthropological Research, 59(4), 433-462.

Koschmieder, K.

2012 Jucusbamba: investigaciones arqueológicas y motivos chachapoya en el norte de la Provincia de Luya, Departamento Amazonas, Peru. Lima.

2014 Asentamientos chachapoya en el norte de la Provincia de Luya, Departamento de Amazonas, Arqueología y Sociedad 28, 71-114.

Koschmieder, K., T.E. Rosales Tham y C. Gaither

2014 Algunas consideraciones acerca del hallazgo de una flauta globular de caracol marino en un contexto funerario Chachapoya (Provincia de Luya, Departamento de Amazonas), Archaeobios 9(1), 27-40.

Kosiba, S. y V.G. Blanco

2013 Construyendo un paisaje Inka: la conversión de los centros ceremoniales y la constitución de la autoridad durante la formación del Estado inkaiko (Cusco, Perú), Arqueología y Sociedad 26, 301-338.

Lamana, G.

2008 Domination without dominance: Inca-Spanish encounters in early colonial Peru, Duke University Press, Durham.

Lefebvre, $\mathrm{H}$.

1991 The production of space [taducción de D. Nicholson-Smith], Blackwell, Oxford.

Lerche, $P$.

1995 Los chachapoya y los simbolos de su historia, Ediciones y Servicios Gráficos

César Gayoso, Lima.

Low, $S$.

1995 Indigenous architecture and the Spanish American plaza in Mesoamerica and the Caribbean, American Anthropologist New Series 94(4), 748-762.

Martínez de Compañón, M.J.

1792 Descripción corográfica de la Provincia de Chachapoyas, Mercurio Peruano (5)165/166, 214-229. Accesso por Biblioteca Virtual Miguel de Cervantes, Biblioteca Nacional del Perú.

Miranda, C. de

1925 [1583] Relación hecha por el Virrey D. Martin Enriquez de los oficias que se proven en la gobernacion de los reinos y provincias del Perú, en Gobernantes del Perú Cartas y Papeles Siglo XVI: Documentos del Archivo de Indias Tomo IX El Virrey Martin Enriquez 1581-1583, Imprenta de Juan Pueyo, Madrid, 114-230.

Morales Gamarra, R., L.V. Álvarez, W. Church y L.C. Tello

2002 Los Pinchudos: un estudio preliminar de su población, Sían 8(12), 3-41.

Morris, C.

2004 Enclosures of Power, en: S.T. Evans y J. Pillsbury (eds.), Palaces of the Ancient New World, 299-324, Dumbarton Oaks, Washington D.C.

Murra, J. V.

1980 The economic organization of the Inka state, JAI Press, Greenwich.

1982 The mit'a obligations of ethnic groups to the Inka state, en: G. Collier, R. Rosaldo, y J. Wirth (eds.), The Inca and Aztec States 1400-1800, 237-262, Academic Press, New York.

1985 «el archipielago vertical» revisited, en: S. Masuda, I. Shimada, y C. Morris (eds.), Andean ecology and civilization: an interdisciplinary perspective on Andean ecological complementarity, 3-13, University Press of Tokyo, Tokyo.

Mumford, J.R.

2012 Vertical empire: the general resettlement of Indians in the colonial Andes, Duke University Press, Durham. 


\section{Muscutt, K.}

1998 Warriors of the clouds: a lost civilization in the upper Amazon of Peru, University of New Mexico Press, Albuquerque.

Nair, S. y J. Protzen

2015 The inka built environment, en: I. Shimada (ed.), The Inka empire: a multidisciplinary approach, 215-232, University of Texas Press, Austin.

Narváez Vargas, A.

1987 Kuelap: una ciudad fortificada en los Andes nor-orientales de Amazonas, Perú, en: V. R. Flores (ed.), Arquitectura y arqueología: pasado y futuro de la construcción en el Perú, 115-142, Chiclayo-Museo Brüning, Chiclayo.

1996 La fortaleza de Kuelap, Arkinka 13, 90-98.

\section{Navaro-Yashin, Y.}

2012 The make-believe space: affective geography in a postwar polity, Duke University Press, Durham.

\section{Nystrom, K.C., J.E. Buikstra y K. Muscutt}

2010 Chachapoya mortuary behavior: a consideration of method and meaning, Chungara: Revista de Antropologia Chilena 42(2), 477-495.

Owen, B.

2012 The metals from Machu Picchu in the context of Inka and regional metalworking traditions, en: R. L. Burger y L. C. Burger (eds.), 1912 Yale peruvian scientific expedition collections from Machu Picchu: metal artifacts, 75-190, Yale University Publications in Anthropology, New Haven.

Raimondi, A.

1874 El Perú, Parte preliminar (Tomo 1), Imprenta del Estado, Lima.

Ramírez, S. E.

2005 To feed and be fed: the cosmological bases of authority and identity in the Andes, Stanford University Press, Stanford.

Ramos, G.

2011 Language and society in early colonial Peru, en: A. J. Pearce (ed.) History and language in the Andes, 1938, Palgrave Macmillan, New York.

Reichlen, P. y H. Reichlen

1950 Recherches archéologiques dans les Andes du Haut Utcubamba, Journal de la Société des Américanistes, 39, 219-246.

Ruiz Barcellos, J.

2001 El complejo arqueológico Purum Llacta, informe preliminar de investigación arqueológica entregado al Instituto Nacional de Cultura-Chachapoyas.

2011 «Chachapuya» $\mathbf{y}$ «Purum»: identidad y simbolización ancestral de una sociedad tardía en el Departamento de Amazonas, Arqueología y Sociedad 23, 1-22.

2013 Purun Llacta y Yálape, dos Miradas para Kuélap, en: Los Chachapoyas, 214-220, BCP, Lima.

Ruiz Estrada, A.

2004 Purumllacta: un Centro administativo incaico en Chachapoyas, Investigaciones Sociales 8(13), 73-84.

2009 La alfarería de Kuelap: tradición y cambio, Avqui Ediciones, Lima.

2011 La mita de Chachapoyas del año 1586, Investigaciones Sociales 15(27), 405-420.

\section{Schjellerup, I.R.}

1984 Cochabamba: an Inca administrative center in the rebellious province of Chachapoyas, International Congress of Americanists, BAR International Series 210, 161-187, Manchester.

2005 Incas y españoles en la conquista de los Chachapoya, Fondo Editorial PUCP, Lima.

2008 Sacando a los caciques de la oscuridad del olvido. Etnias chachpoya y chilcho, Bulletin de I'Institut Français d'Études Andines 37(1), 111-122.

2015 Over the mountains, down into the Ceja de Selva: inka strategies and impacts in the Chachapoyas Region, en: I. Shimada (ed.), The Inka Empire: a multidisciplinary approach, 307-324, University of Texas Press, Austin. 


\section{Schreiber, K.J.}

1993 The Inca occupation of the Province of Andamarca Lucanas, Peru, en: M. Malpass (ed.), Provincial Inca: archaeological and ethnohistorical assessment of the impact of the Inca State, 77-116, University of Iowa Press, Iowa City.

Shimada, I. y J.L. Fitzsimmons (eds.)

2015 Living with the dead in the Andes, University of Arizona Press, Tucson.

Soja, E.W.

1980 The socio-spatial dialectic, Annals of the Association of American Geographers 70 (2), 207-225.

\section{Stanish, C. y L. Coben}

2013 Barter markets in the pre-Hispanic Andes, en: K.G. Hirth y J. Pillsbury (eds.) Merchants, markets, and exchange in the pre-Columbian world, 419-434, Dumbarton Oaks, Washington, D.C.

\section{Stern, S.J.}

1993 Peru's Indian peoples and the challenge of the Spanish conquest: Huamanga to 1640, 2da edición, University of Wisconsin Press, Madison.

Swenson, E.

2014 The materialities of place making in the ancient Andes: a critical appraisal of the ontological turn in archaeological interpretation, Journal of Archaeological Method and Theory 22(3), 677-712.

Thompson, D.E.

1976 Prehistory of the Uchucmarca Valley in the north highlands of Peru, Actas del XLI Congreso Internacional de Americanistas, vol. II, 99-106, México, D.F.

Topic, J.R. y T.L Topic

1993 A summary of the Inca occupation of Huamachuco, en: M. Malpass (ed.), Provincial Inca: archaeological and ethnohistorical assessment of the impact of the Inca State, 17-43, University of Iowa Press, Iowa City.

Toyne, J.M. y L.A. Narváez

2014 The fall of Kuelap: Bioarchaeological analysis of death and destruction on the eastern slopes of the Andes, en: A.K. Scherer y J.W. Verano (eds.), Embattled bodies, embattled places: war in pre-Columbian Mesoamerica and the Andes, 341-364, Dumbarton Oaks Research Library and Collection, Washington, D.C.

VanValkenburgh, P.N.

2012 Building subjects: landscapes of forced resettlement in the Zaña and Chamán Valleys, Peru, $16^{\text {th }}$ and $17^{\text {th }}$ Centuries C.E., tesis de doctorado, Department of Anthropology, Harvard University, Cambridge.

VanValkenburgh, P.N. S.J. Kelloway, L. Dussubieux, J. Quilster y M.D. Glascock

2015 The production and circulation of indigenous lead-glazed ceramics in northern Peru during Spanish colonial times, Journal of Archaeological Science 61, 172-185.

Weizman, E.

2007 Hollow land: Israel's architecture of occupation, Verso, London.

Wernke, S.A.

2012 Negotiated settlements: Andean communities and landscapes under Inka and Spanish colonialism, University of Florida Press, Gainesville.

Wild, E.M., S. Guillen, W. Kutschera, H. Seidler y P. Steier

2007 Radiocarbon dating of the Peruvian Chachapoya/Inca site at the Laguna de los Condores, Nuclear Instruments and Methods in Physics Research B 259, 378-383.

Zucchi, A.

2006 Churches as Catholic burial places: excavations at the San Francisco Church, Venezuela, Historical Archaeology 40(2), 57-68. 
